\title{
In vitro studies provide insight into effects of Dicer-2 helicase mutations in Drosophila melanogaster
}

\author{
HELEN M. DONELICK, ${ }^{1,5}$ LOÏC TALIDE, ${ }^{2,5}$ MATTHIEU BELLET, ${ }^{2}$ P. JOSEPH ARUSCAVAGE, ${ }^{1}$ EMILIE LAURET, ${ }^{2}$ \\ ERIC R.G.R. AGUIAR, ${ }^{3}$ JOAO T. MARQUES, ${ }^{2,4}$ CARINE MEIGNIN, $^{2}$ and BRENDA L. BASS ${ }^{1}$ \\ ${ }^{1}$ Department of Biochemistry, University of Utah, Salt Lake City, Utah 84112, USA \\ ${ }^{2}$ Université de Strasbourg, CNRS UPR9022, Institut de Biologie Moléculaire et Cellulaire, 67084 Strasbourg, France \\ ${ }^{3}$ Centro de Biotecnologia e Genética, Universidade Estadual de Santa Cruz, Ilhéus 45662-900, Bahia, Brazil \\ ${ }^{4}$ Department of Biochemistry and Immunology, Universidade Federal de Minas Gerais, Belo Horizonte, CEP 31270-901, Brazil
}

\begin{abstract}
In vitro, Drosophila melanogaster Dicer-2 (Dcr-2) uses its helicase domain to initiate processing of dsRNA with blunt (BLT) termini, and its Platform $\bullet P A Z$ domain to initiate processing of dsRNA with $3^{\prime}$ overhangs (ovrs). To understand the relationship of these in vitro observations to roles of Dcr-2 in vivo, we compared in vitro effects of two helicase mutations to their impact on production of endogenous and viral siRNAs in flies. Consistent with the importance of the helicase domain in processing BLT dsRNA, both point mutations eliminated processing of BLT, but not $3^{\prime}$ ovr, dsRNA in vitro. However, the mutations had different effects in vivo. A point mutation in the Walker A motif of the Hel1 subdomain, G31R, largely eliminated production of siRNAs in vivo, while F225G, located in the Hel2 subdomain, showed reduced levels of endogenous siRNAs, but did not significantly affect virus-derived siRNAs. In vitro assays monitoring dsRNA cleavage, dsRNA binding, ATP hydrolysis, and binding of the accessory factor Loquacious-PD provided insight into the different effects of the mutations on processing of different sources of dsRNA in flies. Our in vitro studies suggest effects of the mutations in vivo relate to their effects on ATPase activity, dsRNA binding, and interactions with Loquacious-PD. Our studies emphasize the importance of future studies to characterize dsRNA termini as they exist in Drosophila and other animals.
\end{abstract}

Keywords: RNAi; innate immunity; antiviral; dsRNA

\section{INTRODUCTION}

Many animals encode a single Dicer enzyme, but Drosophila melanogaster, like other arthropods (Jia et al. 2017), encodes two Dicers, Dicer-1 (Dcr-1) and Dicer-2 (Dcr-2) (Lee et al. 2004). Dcr-1 is dedicated to microRNA (miRNA) processing, while Dcr-2 is required for small interfering RNA (siRNA) biogenesis (Lee et al. 2004; Carthew and Sontheimer 2009). Dcr-2 processes both endogenous and viral dsRNAs to produce siRNAs with sense and antisense strands of 21 nucleotides (nts) (Golden et al. 2008). These siRNAs are loaded into the RNA-induced silencing complex (RISC) with the help of a Dcr-2 cofactor, R2D2, for eventual silencing of endogenous or viral RNA transcripts (Liu et al. 2003; Mongelli and Saleh 2016; Talide et al. 2020).

Early studies in flies showed that the helicase domain of Dcr-2 is important for initial steps of RNA interference

${ }^{5}$ These authors contributed equally to this work.

Corresponding authors: bbass@biochem.utah.edu, c.meignin@ ibmc-cnrs.unistra.fr

Article is online at http://www.rnajournal.org/cgi/doi/10.1261/rna. 077289.120.
(RNAi). Drosophila eggs expressing Dcr-2 with a G31R mutation in the Walker A motif, located in helicase subdomain Hel1 (Fig. 1A,B), are unable to process injected dsRNA, but downstream steps are intact since silencing of a targeted mRNA occurs when siRNAs are injected (Lee et al. 2004). In Drosophila, naturally occurring endogenous siRNAs (endo-siRNAs) are produced from dsRNA derived from transposable elements (TEs), cis-natural antisense transcripts (cis-NATs), and long inverted repeat transcripts called hairpin RNAs (hpRNAs) (Chung et al. 2008; Czech et al. 2008; Ghildiyal et al. 2008; Kawamura et al. 2008; Okamura et al. 2008; Watanabe et al. 2008; Harrington et al. 2017). Dcr-2's helicase domain is known to be required to produce normal levels of endo-siRNAs from hpRNAs (Fukunaga et al. 2014), and also for processing viral dsRNA, where mutations in either Hel1 or Hel2 subdomains lead to a weakened antiviral response in flies

(C) 2020 Donelick et al. This article is distributed exclusively by the RNA Society for the first 12 months after the full-issue publication date (see http://rnajournal.cshlp.org/site/misc/terms.xhtml). After 12 months, it is available under a Creative Commons License (Attribution-NonCommercial 4.0 International), as described at http://creativecommons. org/licenses/by-nc/4.0/. 


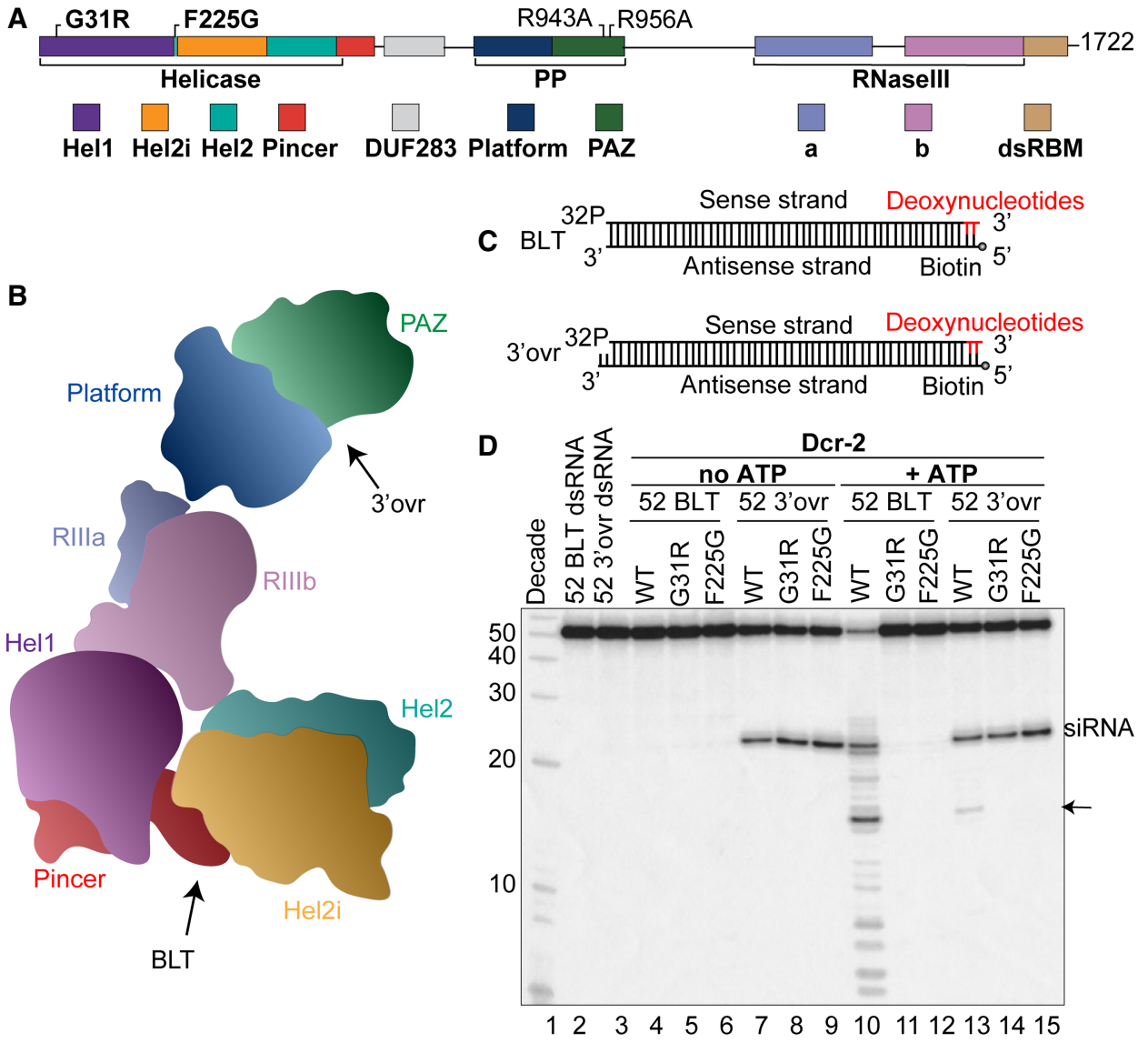

FIGURE 1. Helicase mutations differentially affect processing of BLT and 3 'ovr dsRNA. (A) Schematic of the open-reading frame of Dcr-2. Domains are labeled along with mutations used in this study. (B) Cartoon of the three-dimensional structure of Dcr-2, with subdomains labeled, and arrows pointing to regions of terminus binding sites. (C) Cartoon of dsRNAs used in D, both labeled with ${ }^{32} \mathrm{P}$ on the $5^{\prime}$ end of the sense strand. Modifications that block Dcr-2 binding are indicated on the right side of dsRNAs. (D) Phosphorlmage shows a representative $16 \%$ denaturing polyacrylamide gel monitoring cleavage of BLT or 3'ovr 52-dsRNAs, as shown in C. Cleavage by Dcr-2, WT, or variants as indicated, was assayed without ATP or with (+) $5 \mathrm{mM}$ ATP. The first three lanes on the left show decade size markers (10 nt lengths) and unreacted dsRNA (1 nM). Lanes 415, Dcr-2 $150 \mathrm{nM}$, dsRNA $1 \mathrm{nM}$. siRNA product is labeled; arrow points to $15 \mathrm{nt}$ product.

(Deddouche et al. 2008; Marques et al. 2013; Poirier et al. 2018).

In vitro studies of invertebrate Dicers, including D. melanogaster and $C$. elegans, indicate these Dicers process dsRNA in a termini-dependent manner (Welker et al. 2011; Sinha et al. 2015, 2018). Further, studies using recombinant Dcr-2 show that termini-dependent cleavage involves distinct domains. dsRNA containing a 2 nt $3^{\prime}$ overhang ( $3^{\prime}$ ovr) interacts with Dcr-2's Platform $\bullet P A Z$ domain (Fig. 1A,B) and cleavage by the RNase III domains produces predominantly $22 \mathrm{nt}$ siRNAs in an ATP-independent reaction. In contrast, dsRNA with blunt (BLT) termini is threaded through the helicase domain and cleaved processively. This reaction is dependent on ATP hydrolysis and results in cleavage products of heterogenous sizes, consistent with the threading process (Welker et al. 2011; Sinha et al. 2015, 2018).

The helicase domain of all Dicers shares sequence similarity with the helicase domains of retinoic acid-inducible
gene-I (RIG-I)-like receptors (RLRs) (Fairman-Williams et al. 2010; Luo et al. 2013; Ahmad and Hur 2015). RLRs include helicases essential for the mammalian innate immune response, such as RIG-I, melanoma differentiation-associated 5 (MDA5), and laboratory of genetics and physiology 2 (LGP2). The sequence similarities suggest that the helicase domain of Dicer had a role in antiviral defense in common ancestors, and, interestingly, RIG-I also discriminates the termini of dsRNA, specifically recognizing the triphosphorylated BLT termini of certain viruses (Baum et al. 2010; Schlee 2013; Weber et al. 2013; Weber-Gerlach and Weber 2016). The recognition of BLT dsRNA by the helicase domain of Dcr-2 has led to the proposal that this domain is specialized for recognition of nonself dsRNA, such as viral dsRNA, albeit in vivo studies have not been done to prove this. The termini-dependence of Dcr-2 observed in vitro raises the question of how its naturally occurring endo-siRNA precursors, which are unlikely to have defined termini, are processed. In vitro studies 
show that the dsRNA binding protein (dsRBP) LoquaciousPD (Loqs-PD) results in termini-independent processing of dsRNA (Sinha et al. 2015; Trettin et al. 2017), and, interestingly, while Loqs-PD is important for endogenous dsRNA processing, it is not required for viral siRNA biogenesis, at least for the viruses tested so far (Marques et al. 2013).

In hopes of correlating observations made during in vitro studies of Dcr-2 with its roles in vivo, we studied two point mutations in the helicase domain of Dcr-2 (Fig. 1A, B). F225G is located in the Hel2 subdomain, just prior to the Hel2i insertion (Fig. 1A), and was previously studied because of sequence similarity in its surrounding region to a short region of RIG-I's carboxy-terminal domain (CTD), which includes a phenylalanine that stacks on BLT dsRNA termini (Sinha et al. 2018). In RIG-I, the CTD is carboxy-terminal to the helicase domain, and Dicer enzymes completely lack this domain. However, like RIG-I, Dcr-2 recognizes BLT dsRNA termini, so the short region of sequence similarity suggested a similar role for F225 (Sinha et al. 2018). The second point mutation, $G 31 R$, is located in the Walker A motif of the Hel1 subdomain, and in related helicases is important for ATP binding and hydrolysis (Jankowsky 2011). We characterized effects of these mutations on Dcr-2 activity in vitro, and also studied effects in vivo on processing of endogenous substrates, and during infection with two RNA viruses, Drosophila $C$ virus (DCV) and vesicular stomatitis virus (VSV), positive- and negative-strand RNA viruses, respectively. Our studies validate the importance of the Dcr-2 helicase domain in vivo, both for endo-siRNA biogenesis and the antiviral response. We find that mutations in different regions of the helicase domain lead to diverse, unexpected effects in vivo. Our in vitro studies suggest effects of the two point mutations in vivo relates to their effects on ATPase activity and dsRNA binding.

\section{RESULTS}

\section{Mutations in Dcr-2's helicase domain affect in vitro cleavage of BLT, but not 3'ovr, dsRNA}

To characterize effects of the two point mutations in the helicase domain (Fig. 1A,B), we first performed single-turnover cleavage assays using $5^{\prime}-{ }^{32} \mathrm{P}$-labeled dsRNA containing 52 bp (52-dsRNA; Fig. 1C). These dsRNAs had BLT or 2 nt $3^{\prime}$ ovr termini at one end and were blocked at the other with biotin and deoxynucleotides, so cleavage could be monitored from a single terminus. In the absence of ATP, $\mathrm{Dcr}-2^{\mathrm{WT}}$ and the two variants, Dcr-2 ${ }^{\mathrm{G} 31 \mathrm{R}}$ and $\mathrm{Dcr}-2^{\mathrm{F} 225 \mathrm{G}}$, were unable to cleave BLT 52-dsRNA (Fig 1D, lanes 4-6), but all enzymes showed similar processing of 52-dsRNA with 3'ovr termini (Fig. 1D, lanes 7-9). In contrast, in the presence of ATP, Dcr-2 ${ }^{\text {WT }}$ cleaved BLT dsRNA processively (lane 10), yielding the expected array of heterogeneous products (Welker et al. 2011; Sinha et al. 2015, 2018).
However, no cleavage was observed with the two variants (lanes 11,12), consistent with previous studies, indicating that a functional helicase domain is required for processing BLT dsRNA (Welker et al. 2011; Sinha et al. 2015). Dcr-2 ${ }^{\text {WT }}$ and variants showed similar levels of cleavage of 52dsRNA with $3^{\prime}$ ovr termini in the presence of ATP (lanes 13-15), although slight differences in accumulated siRNA product were observed. A cleavage product at $15 \mathrm{nts}$, indicative of processing by the helicase domain, was observed with Dcr-2 ${ }^{\text {WT }}$ (Fig 1D, lane 13), indicating that a small amount of $3^{\prime}$ ovr dsRNA is processed through the helicase domain in the presence of ATP. In support of the idea that the G31R and F225G point mutations affect helicase function, the ATP-dependent $15 \mathrm{nt}$ band was not observed with these mutant enzymes.

\section{F225G shows an intermediate activity when processing dsRNA from a transgene}

To evaluate effects of the two helicase mutations in Drosophila melanogaster, we used a dcr-2 ${ }^{\text {null }}$ (dicer$2^{\text {L811fsX }}$ genetic background complemented with aminoterminal GFP-tagged Dcr-2. The GFP-fused wild-type Dcr-2 (GFP::Dcr-2 ${ }^{\mathrm{WT}}$ ) allowed direct comparison with GFP fused to Dcr-2 containing each of the helicase point mutations (GFP::Dcr-2 ${ }^{\mathrm{G} 31 \mathrm{R}}$ or GFP::Dcr-2 ${ }^{\mathrm{F} 225 \mathrm{G}}$ ). The fly strains used for our studies also contained a transgene on the $\mathrm{X}$ chromosome, called glass multimer reporter-white inverted repeat $\left(G M R-w^{I R}\right)$, which expresses an inverted repeat dsRNA (IR-dsRNA) only in the eyes. In animals where the RNAi pathway is functional, expression of the transgene induces silencing of the endogenous white gene, resulting in a white eye phenotype (Lee and Carthew 2003; Lee et al. 2004).

Early studies of Dcr-2 in vivo, including the initial characterization of the G31R mutation, used the GMR-w $w^{I R}$ transgene (Lee et al. 2004). Thus, we first compared the two Dcr-2 mutations with this assay (Fig. 2A). As expected, a red eye color was observed for $d c r-2^{\text {null }}$ flies $\left(w^{I R} ; d c r-\right.$ $2^{\text {L811fsX }} / D f$ ), consistent with defective RNAi and the lack of processing of IR-dsRNA, which requires Dcr-2 (Fig. 2A, far left; Lee et al. 2004). As anticipated, introduction of wild-type Dcr-2 ( $\left.w^{I R} ; d_{c r-2}{ }^{L 811 f s X} / D f^{\text {Rescue }}\right)$ or the GFP:: Dcr-2 ${ }^{W T}$ transgene, into the dicer-2 null mutant background restored the white eye phenotype, presumably by allowing a productive RNAi response (Fig. 2A). In contrast, GFP::Dcr-2 ${ }^{\mathrm{G} 31 \mathrm{R}}$ flies had red eyes, nearly identical to $d c r-2^{\text {null }}$ flies, indicating that the helicase mutation G31R resulted in defective RNAi. Given the similar effects of the two point mutations on processing dsRNA in vitro (Fig. 1D), we were surprised to find that strains expressing the GFP::Dcr-2 ${ }^{\text {F225G }}$ transgene had an intermediate phenotype, showing an orange eye color (Fig. 2A). To ensure we were not observing differences in Dcr-2 levels across variants, we normalized dcr-2 mRNA levels to a 
A
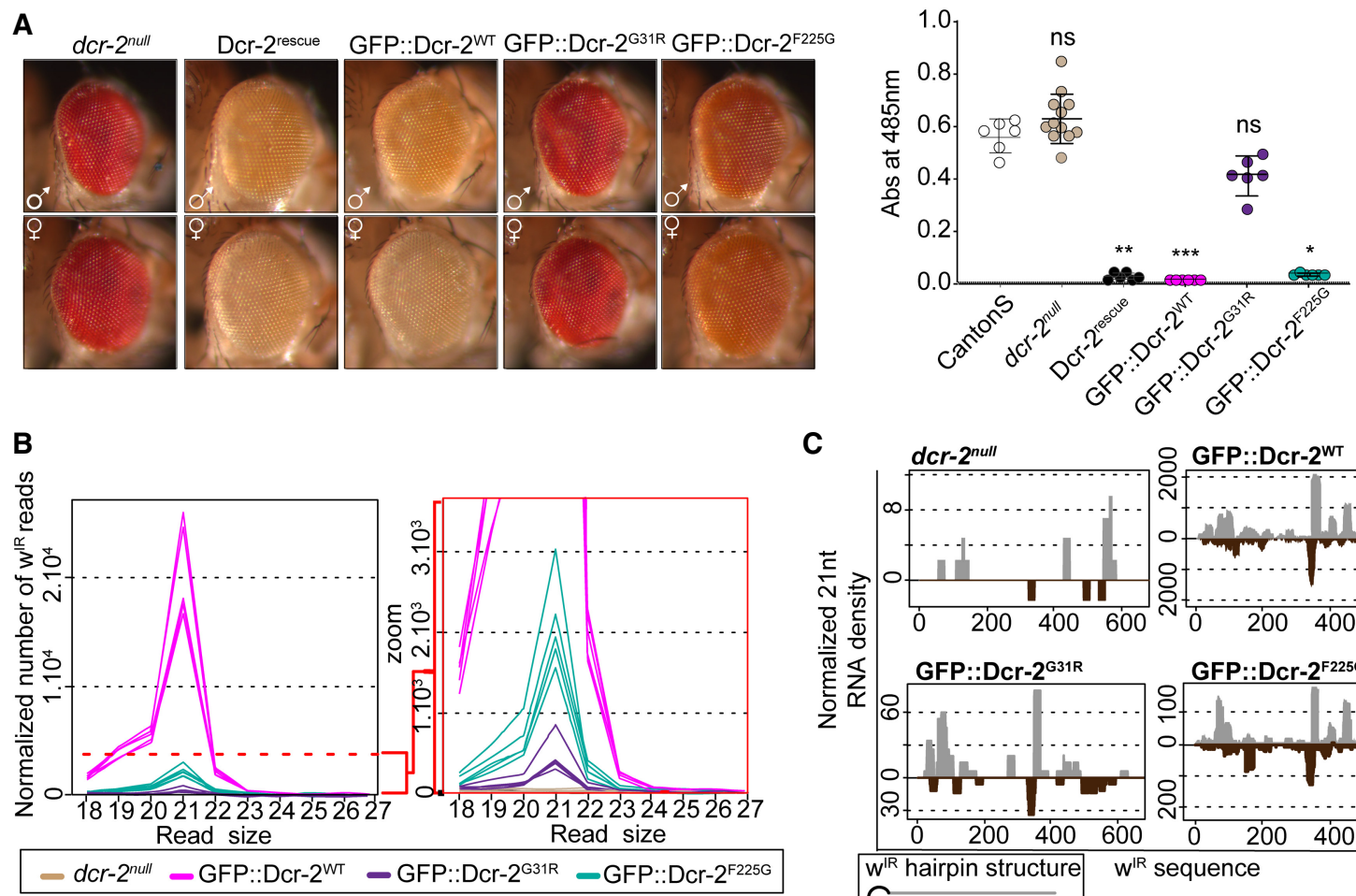

c

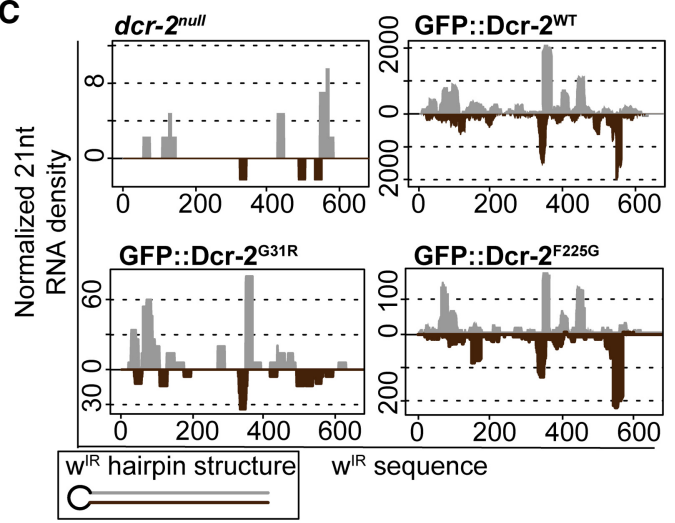

FIGURE 2. Mutations in the helicase domain have different effects on processing of a transgene encoding an inverted repeat hairpin. (A) Eye color of indicated genotypes (see Materials and Methods) is shown on the left panel for representative male and female flies, with absorbance at $485 \mathrm{~nm}$ plotted to the right. Mean shows average of three independent experiments with biological replicates, with each replicate containing 10 female heads; error bars, SD. Each sample is compared to the parental line CantonS. Kruskal-Wallis test. $\left({ }^{*}\right) P<0.05 ;\left({ }^{* *}\right) P<0.01 ;\left({ }^{* * *}\right) P<$ 0.001 ; (ns) not significant. (B) Size distribution of GMR-w $w^{I R}$ mapped reads, normalized to miRNA reads. Replica data sets (libraries) are color coded according to strain, with the right panel showing a magnification of a section of the left plot. Six libraries were analyzed for $d c r-2^{\text {null }}$ and GFP::Dcr$2^{\mathrm{F} 225 \mathrm{G}}$, and five libraries for other genotypes. (C) Representative plots of $w^{I R}$ coverage of $21 \mathrm{nt}$ long siRNAs for indicated strains normalized to the number of miRNAs in each library. Reads were mapped to hairpin sequence and data color coded as in cartoon.

housekeeping gene, RP49, and tested protein levels using western blot (Supplemental Fig. S1A,B). The dcr-2 ${ }^{\text {null }}$ fly had low mRNA levels, and no protein was detectable by western blot, while the GFP::Dcr- $2^{\text {WT }}$ complemented flies showed high levels of $d c r-2$ mRNA and detectable protein levels. There was no significant difference in the mRNA and protein levels for flies expressing GFP::Dcr-2 ${ }^{W T}$, GFP::Dcr-2 ${ }^{\mathrm{G} 31 \mathrm{R}}$, or GFP::Dcr-2 ${ }^{\mathrm{F2} 25 \mathrm{G}}$ (Supplemental Fig. $\mathrm{S} 1 \mathrm{~A}, \mathrm{~B})$.

We also used RNAseq protocols to monitor effects of helicase mutations on levels of siRNA produced from white IR-dsRNA. As expected, GFP ::Dcr-2 ${ }^{W T}$ processed the $w^{I R}$ into many $21 \mathrm{nt}$ products, while no siRNA-sized products were produced with $d c r-2^{\text {null }}$ (Fig. 2B). Consistent with their differential effects on eye color, the two point mutations had different levels of siRNAs. GFP::Dcr-2 $2^{\text {F225G }}$ showed a detectable number of siRNA-sized reads, with levels that were $\sim 10$-fold less compared to Dcr-2 ${ }^{W T}$. However, the levels of siRNAs in GFP::Dcr-2 ${ }^{\mathrm{G} 31 \mathrm{R}}$ were very low, and only slightly higher than $d c r-2^{\text {null }}$ (Fig. 2B). Although the number of reads mapping to each position of the IR-dsRNA varied between strains, the overall pattern for GFP::Dcr-2 ${ }^{\mathrm{WT}}$ and variants were similar to one another (Fig. 2C).

\section{F225G shows an intermediate activity when processing endogenous siRNAs}

The eye color assay monitored processing of dsRNA produced from a transgene, and we were interested in determining whether the two point mutations also had differential effects on processing of naturally occurring endogenous dsRNA. We studied effects of the helicase mutations on processing of two hpRNA precursors, esi-1 and esi-2 (Czech et al. 2008). As expected, in GFP::Dcr-2WT flies, high levels of siRNA reads were observed from processing of both esi-1 and esi-2, while in dcr-2 ${ }^{\text {null }}$ flies, siRNA-sized reads were not observed (Fig. 3A). Similar to $w^{I R}$ processing, in the GFP::Dcr-2 $2^{\mathrm{F} 225 \mathrm{G}}$ flies, a measurable amount of siRNA-sized products was observed, but levels were 10-25-fold less than GFP::Dcr-2 ${ }^{\text {WT }}$. The low levels of siRNA reads observed in samples from GFP::Dcr- $2^{\mathrm{G} 31 \mathrm{R}}$ flies were indistinguishable from those of the null mutant (Fig. 3A). The effects of the two mutations on processing 
A

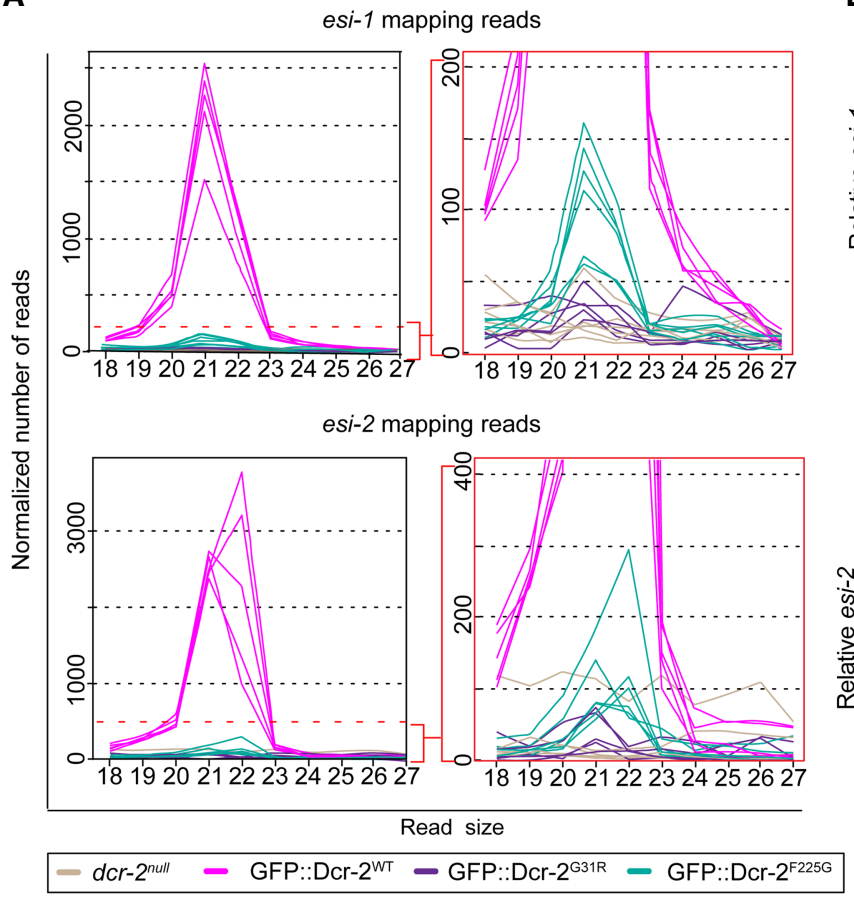

B
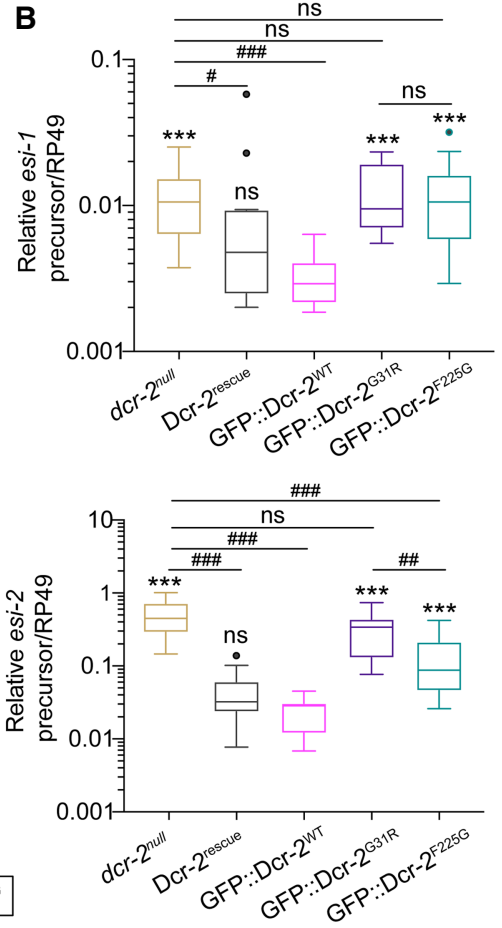

FIGURE 3. Mutations in the helicase domain have differential effects on processing hpRNAs to endo-siRNAs. (A) Size distribution of endo-siRNAs from whole flies derived from esi-1 and esi-2 hpRNA loci normalized to miRNA reads, with graphs to the right showing magnification of indicated regions. Six libraries were analyzed for dcr-2 ${ }^{\text {null }}$ and GFP::Dcr-2 ${ }^{\mathrm{F} 25 \mathrm{G}}$, and five libraries for other genotypes. (B) Levels of esi-1 (top) and esi-2 (bottom) hpRNA precursors as quantified by RT-qPCR in testes ( $n=4$, each with three biological replicates), normalized to the housekeeping gene RP49. Median and interquartile range are represented. All strains compared to GFP::Dcr- $2^{\mathrm{WT}}$, using one-way ANOVA with Tukey correction for multiple comparison. (***) $P<0.001$; (ns) not significant. Horizontal lines show statistics for additional comparisons: (\#) $P<0.05$; (\#\#) $P<$ 0.01 ; (\#\#\#) $P<0.001$; (ns) not significant.

hpRNA precursors were similar to effects on processing of other endo-siRNA precursors found in Drosophila, the TEs and cis-NATs (Supplemental Fig. S2). For these precursors, low, but detectable, levels of endo-siRNAs were observed for GFP::Dcr-2 ${ }^{F 225 G}$ animals, but endo-siRNA levels in GFP::Dcr-2 ${ }^{\mathrm{G} 31 \mathrm{R}}$ flies were indistinguishable from those of $d c r-2^{\text {null }}$ flies.

We also quantified steady-state levels of esi-1 and esi-2 precursors from testes (Fig. 3B). For both esi-1 and esi-2, the $d c r-2^{\text {null }}$ mutant showed high levels of precursors, consistent with the low levels of endo-siRNAs in these animals (Fig. 3A). Similarly, consistent with the high levels of endosiRNAs observed in GFP::Dcr-2 ${ }^{\mathrm{WT}}$ and Dcr-2 ${ }^{\text {Rescue }}$, relatively low levels of precursors were observed. GFP::Dcr$2^{\mathrm{G} 31 \mathrm{R}}$ had significantly higher precursor levels (Fig. 3B), for both esi-1 and esi-2, consistent with the low levels of endogenous siRNAs observed (Fig. 3A). Consistent with the lower levels of endo-siRNAs (Fig. 3A), GFP::Dcr$2^{\mathrm{F} 225 \mathrm{G}}$ testes had a significantly higher level of esi-2 and esi-1 precursors compared to GFP::Dcr-2 ${ }^{\mathrm{WT}}$ (Fig. 3B).

We continued to wonder why the two point mutations looked similar in the in vitro cleavage assay (Fig. 1D), but had distinct effects in vivo. Since both Dcr-2 variants with helicase point mutations were incapable of processing
BLT dsRNA in vitro (Fig. 1D), we presumed cleavage of dsRNA in vivo must be mediated by the Platform $P A Z$ domain, but why the two mutations would have different effects was unclear. To explore cleavage of $3^{\prime}$ ovr dsRNA by Dcr-2 ${ }^{\mathrm{G} 31 \mathrm{R}}$ and $\mathrm{Dcr}-2^{\mathrm{F} 225 \mathrm{G}}$ in more detail, we performed single-turnover cleavage assays over time (Fig. 4A,B). Similar to previous observations, Dcr- ${ }^{\mathrm{WT}}$ processed $\sim 30 \%$ of the $3^{\prime}$ ovr dsRNA in $90 \mathrm{~min}$, in the presence or absence of ATP (Fig. 4A,B; Sinha et al. 2018). While Dcr-2 ${ }^{\text {G31R }}$ showed kinetics similar to that of Dcr-2 ${ }^{\mathrm{WT}}$, Dcr- ${ }^{\mathrm{F} 225 \mathrm{G}}$ processed 3 'ovr dsRNA more efficiently in both conditions, cleaving $\sim 45 \%$ of the dsRNA after $90 \mathrm{~min}$ in the presence and absence of ATP (Fig. 4A,B).

The robust cleavage activity of Dcr-2 ${ }^{\mathrm{F} 225 \mathrm{G}}$ in vitro was consistent with its ability to process IR-dsRNA (Fig. 2) and hpRNA loci (Fig. 3). However, given its robust activity, we wondered why the mutant showed fewer siRNAs than animals expressing wild-type Dcr-2, and considered whether there were defects in binding to Loqs-PD. The Dcr-2 accessory protein Loqs-PD is required for processing endogenous siRNAs (Hartig et al. 2009; Zhou et al. 2009) and cross-linking studies indicate Loqs-PD binds to the Hel2 subdomain of Dcr-2 (Trettin et al. 2017). Using modeling software, we measured the distance between F225 


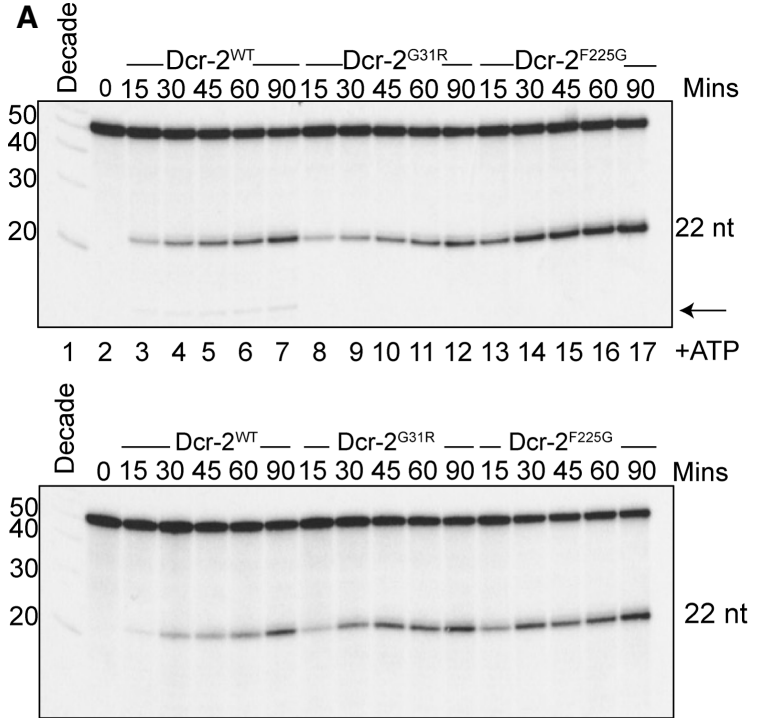

$122 \quad 3 \quad 4556 \quad 7 \quad 8 \quad 91011121314151617$ no ATP

C

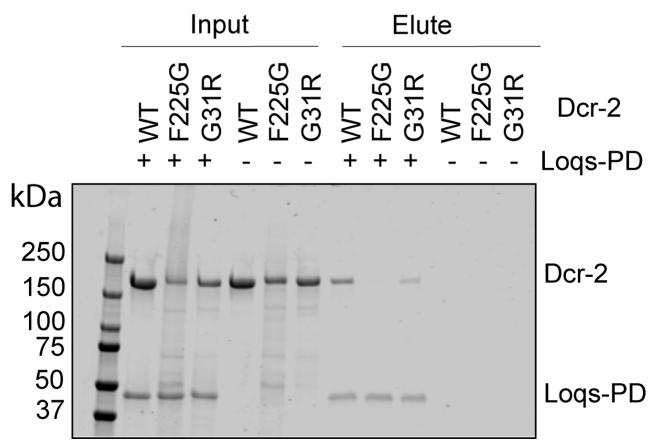

B

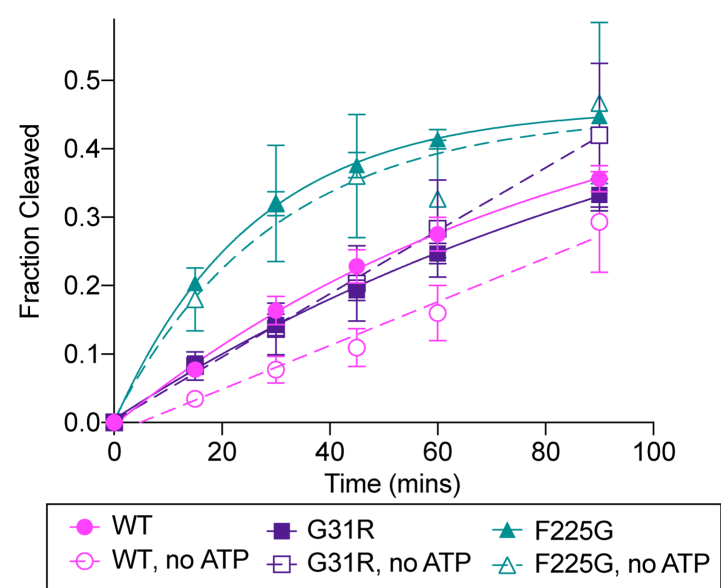

D

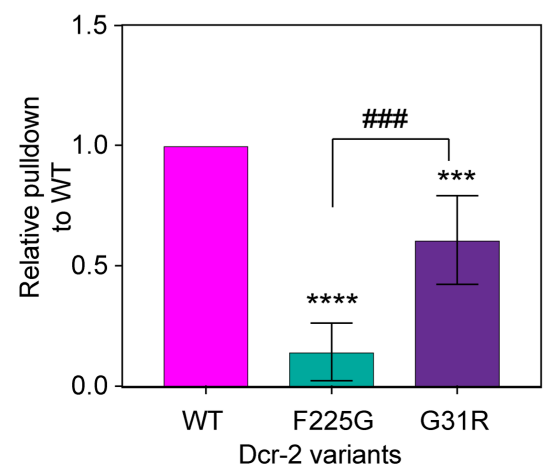

FIGURE 4. Effects of helicase mutations on 3 'ovr dsRNA cleavage and Loqs-PD binding in vitro. (A) Phosphorlmages show representative $16 \%$ denaturing polyacrylamide gels monitoring cleavage of 3 ' ovr dsRNA by Dcr-2 with $5 \mathrm{mM}$ ATP (top), and without ATP (bottom). The arrow points to $15 \mathrm{nt}$ product. (B) Quantification of data as in $A$ (mean $\pm S D, n=3$ ), fit to a pseudo first-order equation, $y=y_{0}+A\left(1-e^{-k t}\right.$ ), where $A=$ amplitude of rate curve, $y_{0}=$ baseline $(\sim 0), k=k_{\text {obs }}$ (first-order rate constant), and $t=$ time $(\mathrm{min})$. (C) Dcr-2 variants, as indicated, were incubated for $60 \mathrm{~min} \pm \mathrm{His}-$ tagged Loqs-PD. Representative 4\%-15\% SDS-polyacrylamide gel stained with Coomassie Brilliant Blue shows input proteins and proteins eluted after pulldown. Far left lane shows molecular weight markers with sizes labeled to the left of the gel. (D) Graph shows quantification of pulldown assay relative to WT protein. $n=4$ (three different protein preparations); error bars, SEM; unpaired Student's t-test as compared to Dcr-2 ${ }^{\mathrm{WT}}$ : $\left(^{* * *}\right) P$ $<0.001$; (***) $P<0.0001$. Additional comparison between Dcr-2 ${ }^{\mathrm{G} 31 \mathrm{R}}$ and Dcr-2 ${ }^{\mathrm{F} 225 \mathrm{G}}$ : (\#\#\#) $P<0.001$. Dcr-2 ${ }^{\mathrm{G} 31 \mathrm{R}}$ and Dcr-2 ${ }^{\mathrm{F} 225 \mathrm{G}}$ purified through Strep-Tactin affinity chromatography only.

and the cross-linking site of Loqs-PD to Dcr-2 (K501); the distance was $\sim 17 \AA$, so it seemed feasible that the F225G mutation might alter Loqs-PD binding.

To investigate this, we performed in vitro pulldown assays by incubating His-tagged Loqs-PD and Dcr-2 variants, and visualized proteins that eluted from nickel resin by SDS PAGE (Fig. 4C,D; Supplemental Fig. S3). As previously observed, Dcr-2 ${ }^{\text {WT }}$ came down with the His-tagged Logs-PD in high quantities (Trettin et al. 2017). However, while both point mutations diminished binding of Dcr-2 to Loqs-PD, Dcr-2 ${ }^{\text {F225G }}$ was bound much less efficiently than Dcr$2^{\mathrm{G} 31 \mathrm{R}}$. Possibly, the robust cleavage of $3^{\prime}$ ovr dsRNA by Dcr-2 ${ }^{\mathrm{F} 225 \mathrm{G}}$, combined with its inefficient binding to Loqs-
$P D$, results in the intermediate phenotypes of this mutant in processing endogenous dsRNAs in vivo.

\section{The helicase point mutations also differentially affect viral infection}

Loqs-PD allows Dcr-2 to process dsRNA in a termini-independent manner and is thought to be important for processing endogenous siRNAs because their precursors have ill-defined termini. However, at least for the viruses tested so far, Loqs-PD is not required for processing viral dsRNA (Marques et al. 2013). Rather, the intrinsic ability of Dcr-2 to discriminate termini has been proposed to be 
important for processing viral dsRNA. In mammals, some viral dsRNAs have BLT termini, and since Dcr-2 can discriminate BLT termini, it has been proposed that like RIG-I, Dcr-2 recognizes BLT termini of viral dsRNA as nonself (Sinha et al. 2018). Thus, as a final test of the effects of the helicase point mutations in Drosophila melanogaster, we monitored infection of flies with DCV and VSV.

DCV encodes a viral suppressor of RNAi (VSR) that binds to dsRNA, inhibiting Dcr-2 processing (Van Rij et al. 2006), and prior studies show that the time course of infection, and survival of infected animals, differs for DCV and VSV viruses (Mueller et al. 2010; Kemp et al. 2013). These prior studies suggested assays of small RNAs $3 \mathrm{~d}$ post infection (DPI) with DCV, and five DPI with VSV, would maximize differences between wild-type and mutant strains while allowing sufficient animals to survive. Thus, we harvested live animals and prepared small RNA libraries for these time points.

Analyses of small RNAs from 17-30 nts showed low levels of small RNAs in all samples, with a clear peak of $21 \mathrm{nts}$ products in certain strains (Fig. 5A; Supplemental Fig. S4A). As previously observed for DCV and other positivestranded viruses (Vodovar et al. 2011), more reads mapped to the genome than the antigenome for DCV. To facilitate comparison, we also determined the ratio of $21 \mathrm{nt}$ reads to other reads between 17-30 nts, for reads matching both the genome and antigenome (Fig. 5B). $d c r-2^{\text {null }}$ flies did not show significant amounts of $21 \mathrm{nts}$ products as compared to other read sizes (Fig. 5A,B; Supplemental Fig. $\mathrm{S} 4 \mathrm{~A}$ ) consistent with prior studies showing that Dcr-2 is required for an efficient antiviral response (Galiana-Arnoux et al. 2006; Wang et al. 2006; Mueller et al. 2010; Marques et al. 2013; Sabin et al. 2013). In contrast, in GFP::Dcr-2 ${ }^{\text {WT }}$ complemented flies, the distribution of reads was concentrated at 21 nts for both viruses, which also agrees with previous studies.

While it is known that Dcr-2's helicase domain is required for an antiviral response (Deddouche et al. 2008; Marques et al. 2013), the two helicase mutants used in our studies impacted viral siRNA levels very differently. Similar to $d c r-2^{\text {null }}$ flies, GFP::Dcr-2 ${ }^{\mathrm{G} 31 \mathrm{R}}$ complemented flies lacked a peak of $21 \mathrm{nt}$ reads that was significantly above background levels (Fig. 5A,B; Supplemental Fig. S4A) for both DCV and VSV infections. However, similar to our analyses of siRNAs produced from endogenous dsRNA, GFP::Dcr-2 ${ }^{\text {F225G }}$ complemented flies showed a
A

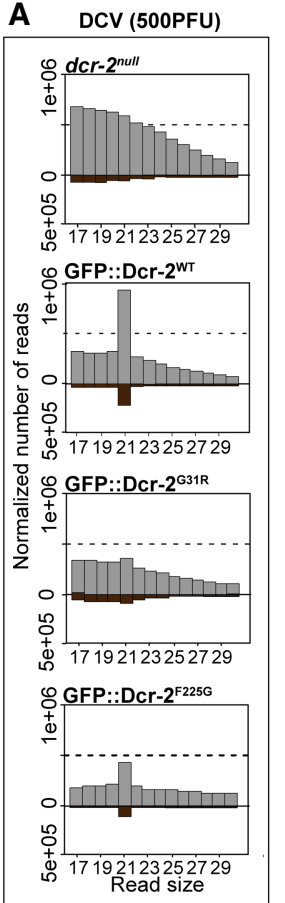

VSV (5000PFU)

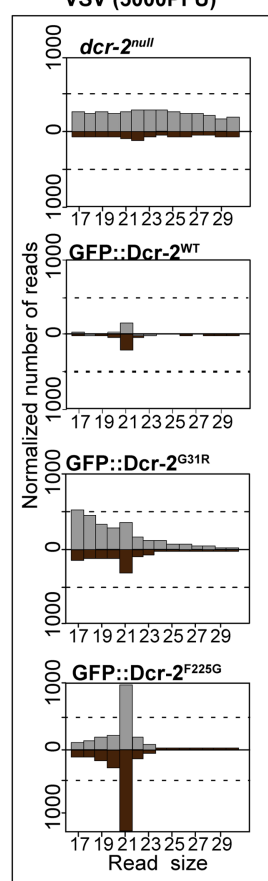

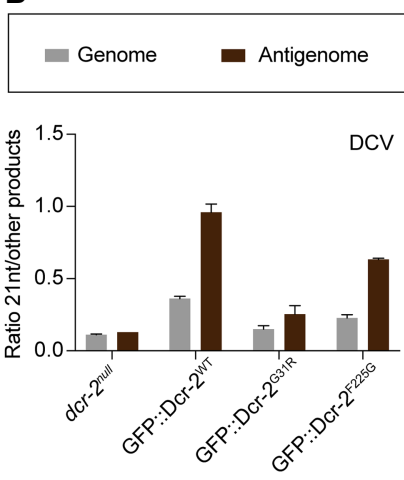

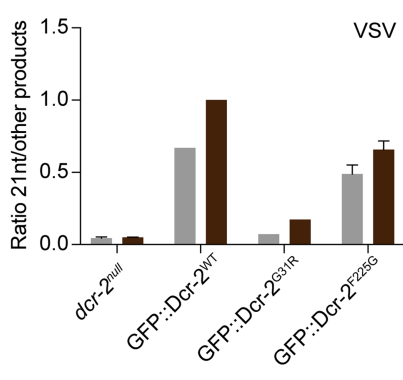

C
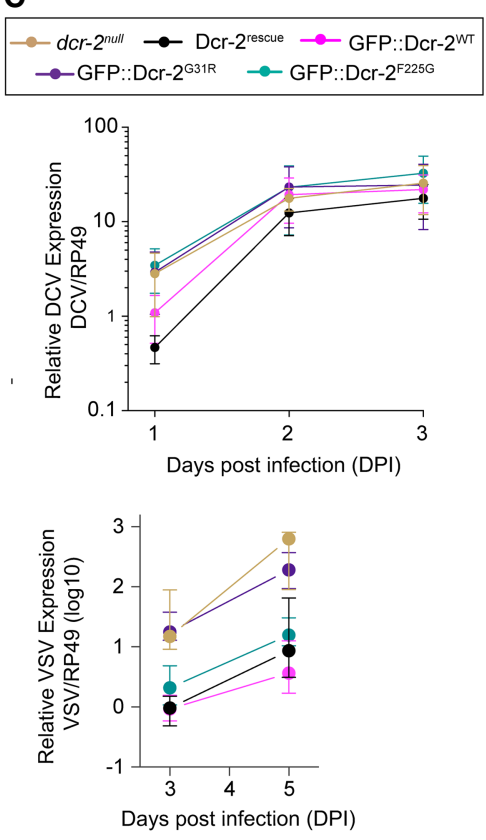

FIGURE 5. Helicase mutations affect processing of viral dsRNA and viral load. (A) Representative data for siRNA reads from one biological replicate mapping to DCV, three DPI (left), and VSV, five DPI (right), normalized to number of miRNA reads (see Supplemental Fig. S4A for additional replicate). (PFU) plaque forming unit. Genome and antigenome reads are colored gray and dark brown, respectively. (B) Comparison of Dcr-2 processing efficiency using the ratio of 21 nts to other product reads (17-30 nts in length) for DCV (top) and VSV (bottom), three and five DPI, respectively. Analysis was done for reads of the genome and antigenome, and data normalized to highest GFP::Dcr- $2^{\text {WT }}$ antigenome ratio. When multiple data sets exist, $n=2$, error bars, SD. (C) Viral load was measured by RT-gPCR for DCV (top) and VSV (bottom), at various days post infection. Normalization was to the housekeeping gene RP49, and data were plotted relative to the earliest time point. $n=3-4$, with at least two biological replicates, with six males and six females in each replicate; error bars, SD. 
clear peak of siRNA-sized products, with levels of siRNAs higher than other read sizes, for both DCV and VSV infections (Fig. 5A,B; Supplemental Fig. S4A). While the number of $21 \mathrm{nt}$ reads was variable between replicates (compare Fig. 5A and Supplemental Fig. S4A), the ratio of $21 \mathrm{nt}$ reads to other reads was fairly constant (Fig. 5B), with GFP::Dcr-2 ${ }^{\mathrm{F} 225 \mathrm{G}}$ flies showing ratios intermediate between GFP::Dcr-2 $2^{\mathrm{WT}}$ and $d c r-2^{\text {null }}$. While it is clear that GFP::Dcr-2 ${ }^{\mathrm{G} 31 \mathrm{R}}$ and GFP:Dcr-2 ${ }^{\mathrm{F} 225 \mathrm{G}}$ flies affect in vivo processing of viral dsRNA differently, we note that it is difficult to relate the levels of viral siRNAs to specific effects on processing by Dcr-2. For example, the levels of $21 \mathrm{nt}$ siRNAs observed in GFP:Dcr-2 $2^{\mathrm{F} 225 \mathrm{G}}$ flies might reflect the cleavage activity of Dcr-2 ${ }^{\mathrm{F} 225 \mathrm{G}}$, as well as any effects on downstream steps, such as the R2D2-mediated passing of the viral siRNA to Argonaute-2 (Ago2) (Mongelli and Saleh 2016; Mussabekova et al. 2017).

We also monitored viral load after infection with DCV and VSV (Fig. 5C; Supplemental Fig. S4B,C). For the fast replicating and VSR-expressing DCV, at three DPI, the time point where viral siRNAs were assayed by RNAseq, infection had reached a plateau, and all strains showed a similar viral load. However, at one DPI, the level of DCV RNA in GFP::Dcr-2 ${ }^{\text {F225G }}$ and GFP::Dcr-2 $2^{\text {G31R }}$ flies was indistinguishable, and similar to the $d c r-2^{\text {null }}$ mutant (Fig. 5C; Supplemental Fig. S4B). A clearer picture was obtained for VSV, revealing that at both three and five DPI, GFP::Dcr-2 ${ }^{F 225 G}$ flies were fighting the virus as efficiently as strains expressing Dcr-2 ${ }^{\mathrm{WT}}$, while GFP::Dcr-2 ${ }^{\mathrm{G} 31 \mathrm{R}}$ flies behaved like the dcr-2 ${ }^{\text {null }}$ mutant (Fig. 5C; Supplemental Fig. S4C).

\section{Dcr-2 helicase mutations also affect dsRNA binding and ATP hydrolysis in vitro}

In three different assays performed in vivo, we observed that flies expressing Dcr-2 ${ }^{\mathrm{G} 31 \mathrm{R}}$ showed more severe consequences on dsRNA processing than those expressing Dcr$2^{\mathrm{F} 225 \mathrm{G}}$. In hopes of providing further insight into this differ- ence, we also monitored effects of the two point mutations on Dcr-2's ability to bind dsRNA, using an electrophoretic mobility shift assay (EMSA). Both mutant proteins bound BLT and 3'ovr dsRNA, and in most cases had lower affinities than Dcr-2 ${ }^{\text {WT }}$ (Table 1; Fig. 6A,B; Supplemental Fig. $S 5 A, B)$. However, despite its inability to process endogenous and viral dsRNA, under all conditions, Dcr-2 ${ }^{\mathrm{G} 31 \mathrm{R}}$ had a higher affinity for dsRNA than Dcr-2 ${ }^{\mathrm{F} 225 \mathrm{G}}$ (Table 1).

The location of the G31R mutation in the Walker A motif, known to be important for binding and hydrolysis of ATP (Linder and Jankowsky 2011) made us look closely at the effects of ATP on binding dsRNA. Consistent with prior studies (Sinha et al. 2018), for Dcr-2WT, the addition of ATP increased affinity for BLT 52-dsRNA, and decreased affinity for 3'ovr 52-dsRNA (Table 1; Fig. 6A,B; Supplemental Fig. S5A). While Dcr-2 ${ }^{\mathrm{G} 31 \mathrm{R}}$ and Dcr-2 ${ }^{\mathrm{F} 225 \mathrm{G}}$ both had lower affinity for binding $3^{\prime}$ ovr compared to Dcr-2 ${ }^{\mathrm{WT}}$, the ATP dependence was maintained, and both mutants showed a decreased affinity for 3'ovr in the presence of ATP (Table 1; Fig. 6B; Supplemental Fig. S5B). However, curiously, the affinity for binding BLT dsRNA was completely independent of ATP for Dcr-2 ${ }^{\mathrm{G} 31 \mathrm{R}}$, while the addition of ATP dramatically reduced the affinity of the Dcr-2 ${ }^{\mathrm{F} 225 \mathrm{G}}$ mutant protein for BLT dsRNA (Table 1; Fig. 6A). The latter result suggested that the differences between Dcr-2 $2^{\mathrm{G} 31 \mathrm{R}}$ and Dcr-2 $2^{\mathrm{F} 225 \mathrm{G}}$ in vivo might be related to ATP binding or hydrolysis.

Since the helicase domain contains the only known ATP binding site in Dcr-2, we assumed that the ATP dependence observed for binding 3'ovr was mediated by the helicase domain. However, to test for possible contributions of the PAZ domain, we studied binding of Dcr-2 and variants that also contained point mutations in the PAZ domain (R943A and R956A, see Fig. 1A) that were previously shown to decrease production of $21 \mathrm{nt}$ siRNAs from 3'ovr dsRNA (Kandasamy and Fukunaga 2016). While binding still occurred for all proteins, the mutations in the PAZ domain eliminated, or severely compromised, the ATP dependence for binding both BLT and 3 'ovr

TABLE 1. Binding affinities calculated from electrophoretic mobility shift assays

\begin{tabular}{|c|c|c|c|c|}
\hline \multirow[b]{3}{*}{ Dcr-2 variant } & \multicolumn{2}{|c|}{52 BLT dsRNA } & \multicolumn{2}{|c|}{$523^{\prime}$ ovr dsRNA } \\
\hline & -ATP & + ATP & -ATP & $+\mathrm{ATP}$ \\
\hline & \multicolumn{4}{|c|}{$K_{\mathrm{d}}(\mathrm{nM})[n=$ replicates $]$} \\
\hline WT & $195.7 \pm 16.4[3]$ & $52.6 \pm 4.3[3]$ & $32.9 \pm 3.4[4]$ & $58.9 \pm 5.1[3]$ \\
\hline$W T^{P A Z}$ & $137.2 \pm 27.1[3]$ & $117.3 \pm 17.7[3]$ & $273.9 \pm 54.4[3]$ & $237.5 \pm 50.1[3]$ \\
\hline G31R & $85.4 \pm 9.1[4]$ & $91.1 \pm 6.6[4]$ & $55.8 \pm 10.0[3]$ & $147.8 \pm 27.9[5]$ \\
\hline$G 31 R^{P A Z}$ & $71.1 \pm 15.4[3]$ & $98.3 \pm 8.0[3]$ & $129.6 \pm 18.1[3]$ & $135.4 \pm 23.3[4]$ \\
\hline F225G & $154.3 \pm 27.3[5]$ & $\geq 400[4]$ & $125.6 \pm 30.0[4]$ & $267.1 \pm 64.2[5]$ \\
\hline $\mathrm{F} 225 \mathrm{G}^{\mathrm{PAZ}}$ & $\geq 400[3]$ & $\geq 400$ [3] & $\geq 400[3]$ & $\geq 400[3]$ \\
\hline
\end{tabular}

$K_{d}$, calculated dissociation constant $\pm \mathrm{SD}$. 

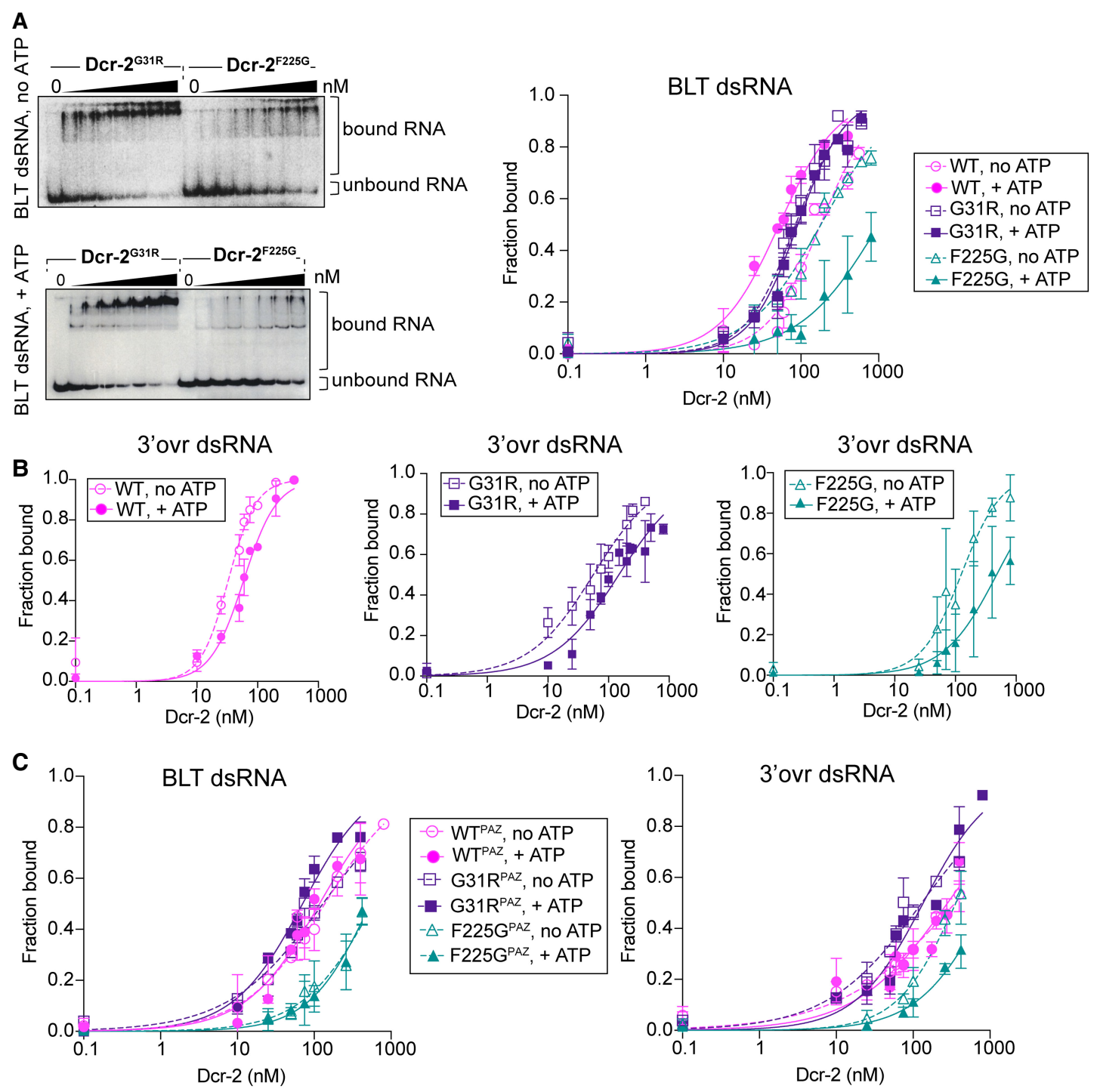

FIGURE 6. Effects of helicase mutations on dsRNA binding. (A) ${ }^{32} \mathrm{P}$-labeled BLT 52-dsRNA was incubated with Dcr-2 ${ }^{\mathrm{WT}}, \mathrm{Dcr}-2^{\mathrm{G} 31 \mathrm{R}}$, or Dcr-2 ${ }^{\mathrm{F} 225 \mathrm{G}}$, $\pm 5 \mathrm{mM}$ ATP as indicated on left of gel. EMSA data were quantified and fit using the Hill formalism (right panel, error bars, SD, $n=3-5$ ), with fraction bound $=1 /\left(1+\left(K_{d}^{n} /[P]^{n}\right)\right)$, where $K_{d}=$ binding affinity and $[P]=$ protein concentration. (B) Quantification of EMSAs (see Supplemental Fig. S5) for $3^{\prime}$ ovr dsRNA binding to Dcr-2 ${ }^{\mathrm{WT}}$, Dcr-2 ${ }^{\mathrm{G} 31 \mathrm{R}}$, or Dcr-2 ${ }^{\mathrm{F} 225 \mathrm{G}} \pm 5 \mathrm{mM}$ ATP. (C) Quantification of EMSAs (see Supplemental Fig. S5) for BLT (left) and $3^{\prime}$ ovr (right) dsRNA binding with Dcr-2 ${ }^{\mathrm{WT}}$, Dcr-2 ${ }^{\mathrm{G} 31 \mathrm{R}}$, or Dcr-2 ${ }^{\mathrm{F} 225 \mathrm{G}}$, with two mutations in the PAZ domain (R943A, R956A) \pm 5 mM ATP. Data were quantified (error bars, SD; $n=3-5$ ) and plotted as in A. Dcr-2 ${ }^{\text {F225G,PAZ }}$ was only purified through Strep-Tactin affinity chromatography. All Dicer proteins contained a wild-type RNase III domain, and some assays showed cleavage products (see Supplemental Fig. S5). Control experiments using proteins with mutations in the RNase III domains showed no significant differences in calculated $K_{d}$ values.

dsRNA (Table 1; Fig. 6C; Supplemental Fig. S4C-E). Thus, in ways that we do not yet understand, the PAZ domain is important for the ATP-dependent reaction.

To further understand the role of ATP in the reaction of the two mutant proteins and their effects in vivo, we monitored their ability to hydrolyze ATP. Our EMSAs showed there were large differences in the affinity of the different proteins for dsRNA, and to specifically focus on differences in ATP hydrolysis, we conducted assays in the presence of saturating amounts of ATP and dsRNA. We incubated ${ }^{32} \mathrm{P}$ $\alpha$-ATP with Dcr-2 and mutant variants, in the absence of
dsRNA (Supplemental Fig. S6), or in the presence of BLT or $3^{\prime}$ ovr dsRNA (Fig. 7A,B) and monitored production of ADP over time using thin-layer chromatography (TLC). As in prior studies (Sinha et al. 2015), for the Dcr-2 ${ }^{\mathrm{WT}}$ enzyme, ATP hydrolysis was inefficient in the absence of dsRNA, and this was also observed for the two mutant proteins (Supplemental Fig. S6A,B). However, as observed previously, the Dcr-2 ${ }^{W T}$ protein showed robust hydrolysis upon addition of BLT or $3^{\prime}$ ovr dsRNA, and hydrolysis was less efficient with 3'ovr dsRNA. Interestingly, ATP hydrolysis catalyzed by Dcr-2 ${ }^{\mathrm{F} 225 \mathrm{G}}$ was indistinguishable from the 
A

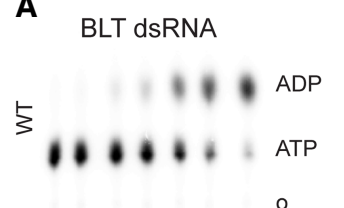

$\begin{array}{llllllll}0 & 1 & 2.5 & 5 & 15 & 30 & 60 & 0 \\ \text { Time (mins) }\end{array}$ 3'ovr dsRNA

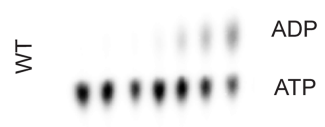

$\underline{0} 12.55153060$ Time (mins)

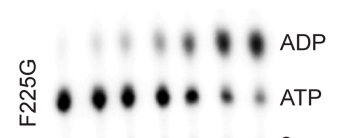

$\begin{array}{lllllll}0 & 1 & 2.55 & 5 & 153060 & \text { Time (min }\end{array}$

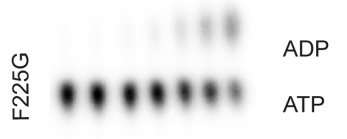

o

012.55153060 Time (mins)

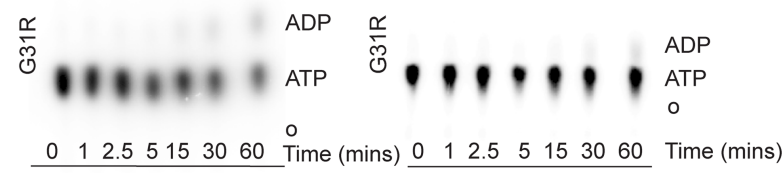

B

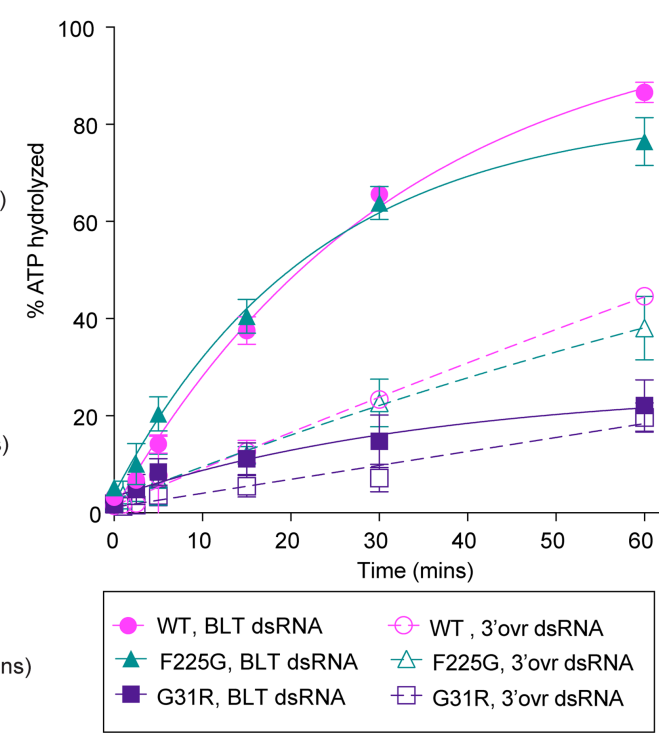

FIGURE 7. Effects of helicase mutations on ATP hydrolysis. (A) Phosphorlmages of representative TLC plates show hydrolysis of $\alpha-{ }^{32} P-A T P$ incubated with Dcr-2 ${ }^{\mathrm{WT}}, \mathrm{Dcr}-2^{\mathrm{F} 225 \mathrm{G}}$, or Dcr-2 ${ }^{\mathrm{G} 31 \mathrm{R}}$, with BLT (left) or $3^{\prime}$ ovr (right) 52-dsRNA, o, origin. (B) Quantification of data from panel A (mean \pm $\mathrm{SD}, n=3$ ) fit with the pseudo first-order equation as in $4 \mathrm{~B}$.

wild-type protein, for both BLT and 3'ovr dsRNA. In contrast, but consistent with the location of the G31R mutation in the Walker A motif (Linder and Jankowsky 2011), Dcr$2^{\mathrm{G} 31 \mathrm{R}}$ was very inefficient at hydrolyzing ATP. For example, for Dcr-2 ${ }^{\mathrm{G} 31 \mathrm{R}}$, BLT dsRNA promoted $\sim 20 \%$ hydrolysis in 60 min, compared to Dcr-2 ${ }^{\mathrm{WT}}$ and Dcr- ${ }^{\mathrm{F} 225 \mathrm{G}}$, which hydrolyzed $\sim 80 \%$ of the ATP in 60 min (Fig. 7A,B). This result provides support for the idea that the different effects of Dcr- $2^{\mathrm{G} 31 \mathrm{R}}$ and Dcr-2 ${ }^{\mathrm{F} 225 \mathrm{G}}$ in vivo relates to their different abilities to bind and/or hydrolyze ATP. Given that the G31R mutation eliminates the ATP dependence of binding to BLT, but not 3'ovr dsRNA, effects on BLT dsRNA binding may require ATP hydrolysis, while effects on $3^{\prime}$ ovr dsRNA binding may only depend on ATP binding.

\section{DISCUSSION}

In this study, we focus on the roles of two amino acids in Dcr-2's helicase domain. Glycine 31 is located in the Walker A motif of helicase subdomain Hel1 (Fig. 1A,B), and many studies emphasize the importance of this motif for ATP binding and hydrolysis (Jankowsky 2011). Consistent with prior studies (Cenik et al. 2011), our in vitro studies of Dcr-2 ${ }^{\mathrm{G} 31 \mathrm{R}}$ showed that this mutant enzyme hydrolyzes ATP poorly (Fig. 7A,B), and in support of the importance of ATP hydrolysis to in vivo functions, we find that flies expressing this mutant variant as their sole Dicer enzyme cannot process endogenous or viral dsRNA (Figs. 2, 3, and 5). The second mutant studied, a phenylalanine at residue 225, is located in subdomain Hel2 of Dcr-2 (Fig. 1A), just amino-terminal to the site of the Hel2i insertion (Jankowsky
2011). Dcr-2 ${ }^{F 225 G}$ hydrolyzes ATP in vitro with an efficiency comparable to Dcr-2 ${ }^{\text {WT }}$ (Fig. 7A,B), and correspondingly, endogenous and viral siRNAs are observed in flies expressing this mutant variant (Figs. 2, 3, and 5). Our studies emphasize the importance of a functional helicase domain for processing endogenous and viral dsRNA in vivo, and this is a clear and important outcome of our studies.

However, the more interesting question addressed by our studies relates to how the helicase-dependent ATP hydrolysis activity of Dcr-2 ${ }^{\mathrm{F} 225 \mathrm{G}}$ contributes to its ability to generate siRNAs in vivo. Biochemical studies (Welker et al. 2011; Sinha et al. 2015) and a cryo-EM structure (Sinha et al. 2018), indicate BLT dsRNA is threaded through Dcr2 's helicase domain in an ATP-dependent manner, resulting in its processive cleavage when it encounters the RNase III active sites. In contrast, dsRNA with a 2 nt $3^{\prime}$ ovr is recognized by the Platform•PAZ domain and cleaved in a helicase- and ATP-independent, distributive manner. Our in vitro studies revealed that neither Dcr- $2^{\mathrm{G} 31 \mathrm{R}}$ or Dcr-2 ${ }^{\mathrm{F} 225 \mathrm{G}}$ can cleave BLT dsRNA, albeit their ability to cleave $3^{\prime}$ ovr dsRNA is retained (Fig. 1D). If Dcr-2 ${ }^{\mathrm{F} 225 \mathrm{G}}$ can only cleave dsRNA with a $3^{\prime}$ ovr, why is its ATP hydrolysis activity important? If only ATP-independent cleavage of 3 'ovr dsRNA occurs in vivo, why cannot Dcr-2 ${ }^{\mathrm{G} 31 \mathrm{R}}$ process endogenous and viral dsRNA?

\section{What are the termini of endogenous and viral dsRNAs expressed in D. melanogaster?}

While it seems likely that the activities of $\mathrm{Dcr}-2^{\mathrm{G} 31 \mathrm{R}}$ and Dcr-2 ${ }^{\text {F225G }}$ in vivo relate to the dsRNA termini they 
encounter, little is known about termini of endogenous or viral dsRNA, in any organism. In Drosophila, precursors of endo-siRNAs are produced from dsRNA arising from antisense transcripts (cis-NATs), transposable elements, and hairpin structures formed from inverted repeats (hpRNAs) (Chung et al. 2008; Czech et al. 2008; Ghildiyal et al. 2008; Kawamura et al. 2008; Okamura et al. 2008; Watanabe et al. 2008; Harrington et al. 2017). While the termini of these precursors have not been characterized, it seems almost certain they are not BLT or $2 \mathrm{nt} 3$ 'ovrs. Rather, it seems likely the termini are long noncomplementary single strands, extending from one or both of the $5^{\prime}$ and $3^{\prime}$ dsRNA termini. In this light, it makes sense that processing of endogenous dsRNA requires Loqs-PD (Zhou et al. 2009; Hartig and Förstemann 2011), which confers termini-independent cleavage using its carboxyl terminus to bind Dcr-2's Hel2 subdomain (Hartig and Förstemann 2011; Sinha et al. 2015; Trettin et al. 2017). Loqs-PD acts in an ATP-dependent manner, and, thus, in the presence of Loqs-PD, both BLT and 3'ovr dsRNA are likely processed through the helicase domain (Sinha et al. 2015; Trettin et al. 2017). Thus, it also makes sense that flies expressing Dcr-2 ${ }^{\mathrm{G} 31 \mathrm{R}}$, which cannot hydrolyze ATP, do not generate Loqs-PD-dependent endo-siRNAs (Fig. 3).

Since Dcr-2 ${ }^{\mathrm{F} 225 \mathrm{G}}$ can hydrolyze ATP, Dcr-2 $2^{\mathrm{F} 225 \mathrm{G}}$ animals might be expected to produce endo-siRNAs at wild-type levels. However, we find Dcr-2 ${ }^{\text {F225G }}$ is severely compromised in its ability to bind Loqs-PD (Fig. 4C,D; Supplemental Fig. S3), consistent with its lower levels of endo-siRNAs. At present, we do not know whether the F225G point mutation affects a specific amino acid interaction between Loqs-PD and Dcr-2's helicase domain, or whether it changes the conformation of Dcr-2 in ways that impact the binding interface. Many of Dcr-2's accessory proteins interact with the helicase domain (Hansen et al. 2020), and it remains possible that the F225G mutation affects the interaction of other proteins, such as R2D2 or Ago2. However, Dcr-2 ${ }^{\mathrm{F} 225 \mathrm{G}}$ flies showed an orange eye color (Fig. 2A), indicating some siRNAs are being passed to Ago2. Additionally, western blot analyses showed the presence of R2D2 (Supplemental Fig. S1B), which is known to interact with the helicase domain (Liu et al. 2006; Nishida et al. 2013). Consistent with an altered conformation, we note that this protein is challenging to purify and required modifications of our protocol (see Materials and Methods).

Determining termini of viral dsRNA is difficult, in part because of the diversity of strategies that viruses use for replication and transcription, which generate complex mixtures of RNA species that include read-through transcripts, abortive replication products, and defective interfering (DI) RNAs. While studies are few, by monitoring immune responses to purified viral intermediates, combined with in vitro biochemistry and structural biology, there is good evidence that the BLT termini of "stem- loops" exemplified by panhandle structures formed by minus strand, single-strand RNA viruses, and those of copyback DI RNAs, trigger the antiviral response mediated by mammalian RIG-I (Baum et al. 2010; Schlee 2013; Weber et al. 2013; Weber-Gerlach and Weber 2016). In our studies, we used two viruses, VSV and DCV. VSV is a negativestrand, single-stranded RNA virus of the Rhabdoviridae family, known to produce DI particles and activate RIG-I (Schlee 2013). VSV has a wide host range (Xu and Cherry 2014) that includes Drosophila melanogaster (Mueller et al. 2010). While it is not a natural Drosophila virus, assuming the virus behaves as in mammals, we would expect VSV to produce viral dsRNA with BLT termini. DCV, a natural pathogen of Drosophila, is a Dicistroviridae, a picornalike virus that, like Picornaviridae, has the small protein VPg at the $5^{\prime}$ end of its genomic RNA (Nakashima and Shibuya 2006). dsRNA with a $5^{\prime}$ cap structure is cleaved poorly by Dcr-2 (Sinha et al. 2018), and we would expect VPg to preclude Dcr-2 binding, although it is known that Dcr-2 is required for an antiviral response against DCV (GalianaArnoux et al. 2006). For both viruses, we observed that Dcr-2 ${ }^{\mathrm{F} 225 \mathrm{G}}$, but not Dcr-2 ${ }^{\mathrm{G} 31 \mathrm{R}}$, could produce viral siRNAs. Possibly the pathway used to produce viral siRNAs when a dsRNA terminus is blocked by VPg is also used by Dcr-2 $2^{\mathrm{F} 225 \mathrm{G}}$, which cannot cleave BLT dsRNA. While Dcr-2 ${ }^{\mathrm{F} 225 \mathrm{G}}$ produced 21 nt viral siRNAs similarly for both viruses (Fig. 5B), viral load assays indicated that it was able to decrease viral load for VSV but not DCV (Fig. 5C). While this difference could relate to differences in the termini of the two viruses, as observed in prior studies, the production of a VSR by DCV may dominate any effects of termini (Han et al. 2011; Petrillo et al. 2013; Bronkhorst et al. 2019).

\section{How does Dcr-2 ${ }^{\mathrm{F} 225 \mathrm{G}}$ produce viral siRNAs in vivo?}

Existing studies indicate Loqs-PD is not required for processing viral dsRNA in Drosophila (Marques et al. 2013). The fact that F225G affects Loqs-PD binding but is still able to produce ample virus-derived siRNAs in vivo reinforces that processing of viral dsRNA does not require Logs-PD. However, it is interesting to speculate that viral dsRNA processing in vivo requires other partners, which could compensate the lower affinity of F225G for dsRNA observed in vitro. In the absence of accessory factors, cleavage of viral dsRNA would have to rely on the intrinsic activity of Dcr-2. While definitive information on the structure of viral dsRNA termini in Drosophila is lacking, since Dcr-2 ${ }^{\mathrm{F} 225 \mathrm{G}}$ can only cleave $3^{\prime}$ ovr dsRNA in vitro (Fig. 1D), we presume any siRNAs observed in flies expressing this mutant enzyme must be generated by the $3^{\prime}$ ovr processing activity. Based on structures of RNase III enzymes (Nicholson 2014), we expect each of the two RNase III active sites of Dcr-2 (Fig. 1A,B) to engage a scissile phosphodiester bond of one strand, but on opposite sides of the 
minor groove, an architecture that yields a double-stranded cleavage product with a 2 nt 3'ovr. While viral dsRNA would not be expected to have $3^{\prime}$ ovr termini, a single spurious cleavage by Dcr-2's RNase III domains, anywhere in the viral dsRNA, would produce a 3 'ovr terminus that would be efficiently recognized by the Platform $\bullet P A Z$ domain.

There are several possible explanations for why production of endogenous and viral siRNAs might require a functional, ATP-dependent helicase domain, even if all cleavages are mediated by $3^{\prime}$ ovr processing. For example, at least some $3^{\prime}$ ovr dsRNA is threaded through the helicase domain of Dcr-2 ${ }^{\mathrm{WT}}$ (e.g., Fig. 1D). Although we cannot exclude the possibility that viral siRNAs are produced by an ATP-dependent threading mechanism, in our in vitro characterization of dsRNA cleavage (Figs. 1D and 4A,B), the 15 nt band indicative of ATP-dependent "threading" is observed with Dcr-2 ${ }^{\text {WT }}$ but neither of the mutant variants. Alternatively, the ATP-dependence might be explained if the interaction of the $3^{\prime}$ ovr with the Platform $\bullet P A Z$ domain is affected by ATP binding or hydrolysis. Cleavage of $3^{\prime}$ ovr dsRNA can occur in the absence of ATP, but addition of ATP to Dcr-2 ${ }^{\text {WT }}$ decreases its affinity for $3^{\prime}$ ovr, and this decrease in affinity is maintained for both Dcr-2 $2^{\mathrm{F} 225 \mathrm{G}}$ and Dcr-2 ${ }^{\mathrm{G} 31 \mathrm{R}}$ (Table 1). Consistent with possible effects of ATP on binding $3^{\prime}$ ovr, mutations in the Platform $\bullet P A Z$ domain eliminated ATP-dependent effects for Dcr-2 ${ }^{\mathrm{WT}}$ and both mutant variants (Fig. 6C). Given the inefficient ATP hydrolysis observed with Dcr-2 ${ }^{\mathrm{G} 31 \mathrm{R}}$, we anticipate that any ATP dependence observed with this enzyme must relate to ATP binding.

\section{Why is Dcr-2 ${ }^{\mathrm{G} 31 \mathrm{R}}$ incapable of processing viral dsRNA in vivo?}

Both Dcr-2 ${ }^{\mathrm{F} 225 \mathrm{G}}$ and Dcr-2 ${ }^{\mathrm{G} 31 \mathrm{R}}$ cleave $3^{\prime}$ ovr dsRNA in the presence or absence of ATP in vitro, and at present we cannot fully explain why only Dcr-2 ${ }^{\text {F225G }}$ can generate viral siRNAs in vivo. However, a clear difference between the two mutant variants is that Dcr-2 ${ }^{\mathrm{F} 225 \mathrm{G}}$, but not $\mathrm{Dcr}-2^{\mathrm{G} 31 \mathrm{R}}$, can efficiently hydrolyze ATP, raising the possibility that this activity is important even if all siRNAs are generated by recognition of $3^{\prime}$ ovrs. One possibility is that ATP hydrolysis is important for generating an initial 3'ovr terminus from viral dsRNA by "spurious" cleavage.

A careful review of the in vitro properties of $\mathrm{Dcr}-2^{\mathrm{G} 31 \mathrm{R}}$ offers other explanations. Like Dcr-2 $2^{\mathrm{WT}}$ and $\mathrm{Dcr}-2^{\mathrm{F} 225 \mathrm{G}}$, binding of $3^{\prime}$ ovr dsRNA to Dcr-2 ${ }^{\mathrm{G} 31 \mathrm{R}}$ is weaker in the presence of ATP (Table 1), and, as mentioned, this suggests that even though ATP hydrolysis is compromised in this variant, ATP binding might still occur. However, in contrast to Dcr-2 ${ }^{\mathrm{WT}}$ and Dcr-2 ${ }^{\mathrm{F} 225 \mathrm{G}}$, the ATP dependence of BLT dsRNA binding is lost in Dcr-2 ${ }^{\mathrm{G} 31 \mathrm{R}}$, although $\mathrm{Dcr}-2^{\mathrm{G} 31 \mathrm{R}}$ readily binds $B L T$ dsRNA, exhibiting a higher affinity for BLT dsRNA than Dcr-2 ${ }^{\text {F225G }}$ (Table 1). Possibly the lack of
ATP hydrolysis activity for Dcr-2 $2^{\mathrm{G} 31 \mathrm{R}}$ traps bound BLT dsRNA in a nonproductive complex. BLT dsRNA might be sequestered by Dcr-2 ${ }^{\mathrm{G} 31 \mathrm{R}}$, and a characterized mutation in the related helicase domain of mammalian RIG-I offers a precedent for such sequestering. In RIG-I, a mutation in the Walker B motif (E3730) results in a protein that still binds ATP, but cannot hydrolyze ATP (Jiang et al. 2011; Lässig et al. 2015). Consistent with a sequestering model, the amount of RNA that copurified with RIG-I ${ }^{\mathrm{E} 373 \mathrm{Q}}$, was three times that of RIG-IWT (Lässig et al. 2015). According to this scenario, the difference between in vivo activities of Dcr-2 $2^{\mathrm{F} 225 \mathrm{G}}$ and $\mathrm{Dcr}-2^{\mathrm{G} 31 \mathrm{R}}$ could be explained by sequestering rather than differences in ATP hydrolysis.

In summary, our studies emphasize the importance of Dcr-2's helicase domain for processing of endogenous and viral dsRNA in Drosophila melanogaster. Our in vitro analyses suggest ways dsRNA is processed in vivo, yet also raise questions about the specific ways that ATP binding and hydrolysis affect processing in vivo. Our results highlight that future studies to determine termini of endogenous and viral dsRNA will be invaluable for a mechanistic understanding of dsRNA processing as it occurs in a living cell.

\section{MATERIALS AND METHODS}

\section{In vitro biochemistry}

Dcr-2 ${ }^{\mathrm{WT}}$ and mutant proteins were produced and purified as described (Sinha and Bass 2017). Protocols were modified slightly to

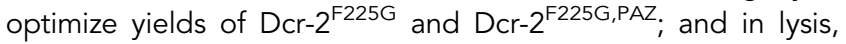
wash, and elution buffer, we used $10 \%$ glycerol instead of $5 \%$. When noted in legends, protein was used after the Strep-Tactin affinity chromatography step, with all other preparations using the three-step purification scheme. Blunt and 3'ovr dsRNA substrate was produced and $5^{\prime}$ end-labeled with ${ }^{32} \mathrm{P}$ as described (Sinha et al. 2018), and used in cleavage assays as described (Sinha et al. 2015, 2018), except 150 nM of Dcr-2 was used instead of $30 \mathrm{nM}$. Electrophoretic mobility shift assays were as described previously (Sinha et al. 2015, 2018), as well as ATP hydrolysis reactions (Sinha et al. 2015) and pulldown assays (Trettin et al. 2017).

\section{Drosophila genetics, fly maintenance, and injections}

The genotypes dcr- $2^{\text {null }}\left[w^{I R} ;\right.$ dicer- $\left.2^{L 811 f s X} / D f\right], D c r-2^{\text {Rescue }}\left[w^{I R}\right.$; dicer-2 $\left.2^{\text {L811fsX }} / D f, D c r-2^{\text {Rescue }}\right]$, GFP::Dcr-2 ${ }^{W T}\left[w^{\text {IR }}\right.$; dicer-2 ${ }^{\text {L811fs } X}$; GFP::Dcr-2 $\left.{ }^{W T}\right]$ GFP::Dcr-2 ${ }^{\mathrm{G} 31 \mathrm{R}} \quad\left[w^{\text {IR }} ;\right.$ dicer- $^{\text {L811fsX }} ;$ GFP.:Dcr$\left.2^{\mathrm{G} 31 \mathrm{R}}\right]$, and GFP.:Dcr-2 $2^{\mathrm{F} 225 \mathrm{G}}\left[w^{I R} ;\right.$ dicer-2 $\left.{ }^{\text {L811fsX }} ; \mathrm{GFP} .: \mathrm{Dcr}-2^{\mathrm{F} 225 \mathrm{G}}\right]$ were generated as described below and in the next section. $d c r-2^{\text {null }}$ mutant flies ( $d c r-2^{\text {L811fs } X}$ ) (Lee et al. 2004) were crossed with the deficiency Df(2R) BSC45 (Bloomington stock \#7441) or the Df(2R)BSC45-Dcr-2 ${ }^{\text {Rescue }}$ (Kemp et al. 2013) lines. All flies contained the GMR-w ${ }^{I R}$ transgene (Lee and Carthew 2003) located on the X-chromosome. Flies were fed on standard cornmealagar medium at $25^{\circ} \mathrm{C}$ and were Wolbachia-free. Different genotypes were obtained by crossing, and collected as F1 at 0-3 d 
old. After three additional days on fresh food (flies are then 3-6 d old), $4.6 \mathrm{~nL}$ of either TRIS (10 mM, pH7.5), DCV (500PFU), or VSV (5000PFU) solutions were injected by intrathoracic injection (Nanoject II apparatus; Drummond Scientific). Flies were kept at $25^{\circ} \mathrm{C}$ for 3 (TRIS and DCV condition) to 5 (VSV condition) days. DCV and VSV virus stocks were produced as described (Kemp et al. 2013).

\section{Establishment of GFP::Dcr-2 complemented flies}

Dcr-2 cDNA was transferred to in-house Drosophila melanogaster transgenic expression vectors by LR recombination using the Gateway LR clonase II enzyme mix (Invitrogen). We established a transgenic vector allowing expression of GFP.:Dcr-2 under the control of the polyubiquitin promotor with a specific site insertion in the Drosophila melanogaster genome (kindly provided by Jean-René Huynh's laboratory [DGRC\#1282]). The polyubiquitin promotor was cloned into UASt-attB Pmel V, provided by JeanMarc Reichhart, which contained the mini-white gene as a marker, 5xUASt followed by a polylinker, an SV40 termination site, and an attB cassette allowing site specific insertion in flies containing attP site. The GFP-amino-terminal gateway cassette (Kpnl-Bglll of 2,959bp) was inserted at the restriction sites Kpnl-BamHI using One Shot ccdB Survival competent cells (Thermo Fisher). As we previously validated that an amino-terminal GFP fusion of Dcr-2 under the polyubiquitin promotor inserted at independent sites of the Drosophila genome rescued RNAi (Girardi et al. 2015), we generated several GFP-Dcr-2 variants by PCR mutagenesis and inserted each into the same genomic site to facilitate comparison of the transgenic lines. The GFP::Dcr-2 constructs were all inserted on the third chromosome at position 89E11 (BL\#9744) generated by BestGene. Depending on the experiment, flies were crossed with a deficiency covering the $d c r-2$ gene to obtain hemizygote flies for dcr-2 [ $\left.w^{I R} ; \mathrm{Df}(2 \mathrm{R}) \mathrm{BSC} 45 / \mathrm{CyO}\right]$, the $d c r-2^{\text {null }}$ allele $\left[w^{I R} ; d c r-2^{L 811 f s X} / C y O\right]$, or the genomic rescue for the $d c r-2$ gene [ $w^{I R} ; \mathrm{Df}(2 \mathrm{R}) \mathrm{BSC} 45, \mathrm{Dcr}-2^{\text {Rescue}} / \mathrm{CyO}$ ] described in Kemp et al. (2013). mRNA from GFP::Dcr-2 complemented flies was quantified by RT-qPCR. Primer sequences are in Supplemental Table S1.

\section{Eye color quantification}

For each sample, 10 heads of female flies aged from 3 to $5 \mathrm{~d}$ were frozen in liquid nitrogen and homogenized twice at $25 \mathrm{~Hz}$. An amount of $1 \mathrm{~mL}$ of AEA (solution with $30 \% \mathrm{EtOH}, 1 \% \mathrm{HCl}$ ) was added and color analyzed with a spectrophotometer at $485 \mathrm{~nm}$ (Maas 1948).

\section{RT-qPCR}

Total RNA extractions from flies (six males, six females) and dissected testes (10 males) were as described (Goto et al. 2018). Reverse transcription of $1 \mu \mathrm{g}$ of RNA was using the iScript gDNA Clear cDNA synthesis kit (Bio-Rad) according to manufacturer's instructions. See Supplemental Table S2 for primer sequences.

\section{Antibodies and immunoblot analysis}

Sixty flies (30 males, 30 females) of each genotype were collected and frozen overnight at $-80^{\circ} \mathrm{C}$ in Precellys tubes with ceramic beads. Flies were first shredded without any additional liquid and a second time with lysis buffer (30 mM HEPES KOH pH 7.5, $50 \mathrm{mM} \mathrm{NaCl}, 2 \mathrm{mM} \mathrm{Mg}(\mathrm{OAc})_{2}, 1 \% \mathrm{NP} 40,2 \mathrm{X}$ cOmplete Protease Inhibitor Cocktail [Roche]). Protein $(60 \mu \mathrm{g})$ was used for immunoblot analysis. Membranes were blocked with $5 \%$ nonfat dry milk in $0.3 \%$ PBS-Tween for $1 \mathrm{~h}$ at room temperature and incubated overnight at $4{ }^{\circ} \mathrm{C}$ with primary antibody in $2 \%$ nonfat dry milk and $0.3 \%$ PBS-Tween. After washing, secondary antibody fused to horseradish peroxidase (HRP) was added to the membrane in 2\% nonfat dry milk and 0.3\% PBS-Tween for $1 \mathrm{~h}$ at room temperature. Membranes were then washed and visualized with enhanced chemiluminescence reagent (GE Healthcare) in a ChemiDoc (Bio-Rad) apparatus. See Supplemental Table S3 for antibody details.

\section{Small RNA sequencing}

Total RNA extraction of infected and noninfected flies (three males, three females) used TRIzol (Thermo Fisher Scientific), following manufacturers' instructions. RNA quality was assessed with an Agilent Bioanalyzer 2100 (Agilent), using the Eukaryote Total RNA Nano assay. Libraries for small RNA sequencing were prepared using the NEBNext Multiplex Small RNA Library Prep Set for Illumina (NEB) with the following modifications of manufacturers' protocol: custom RNA adaptors were used for individual libraries instead of the 5' SR Adaptor; for sequencing small RNA of flies, an additional $2 S$ rRNA blocking primer was added to the step of hybridization of RT primers. Size selection after final PCR amplification followed the $6 \%$ nondenaturing acrylamide gel method described in the protocol. Quality of libraries was assessed using a bioanalyzer with a DNA 1000 chip (Agilent). Libraries were sequenced in Illumina HiSeq 4000 (Illumina), with a single-end 50 bp read-length strategy.

After quality trimming and adaptor removal using Trimmomatic v0.36 (Bolger et al. 2014), reads were mapped sequentially using bowtie v1.1.2 (Langmead et al. 2009) to the following references: DCV (NC_001834.1), VSV (EU849003.1), esi1 (FBgn0285991), esi2 (FBgn0285992), w ${ }^{I R}$ (Exon 3 of FBgn0003996), cis-NAT regions (Fukunaga et al. 2012), and transposable elements (FlyBase annotation, version $r$ 6.13). Normalization of libraries within the same sequencing lane was done by applying a factor reflecting the proportion of 21-23 nt long reads mapping to Drosophila miRNA hairpins.

\section{DATA DEPOSITION}

The SRA accession number for the small RNA libraries is PRJNA646624.

\section{SUPPLEMENTAL MATERIAL}

Supplemental material is available for this article. 


\section{ACKNOWLEDGMENTS}

We thank members of the Bass, Meignin, and Marques laboratories for reagents and helpful discussions, and Drs. Peter Shen and Jean-Luc Imler for advice and helpful discussions. We thank Dr. Sarah Hansen and Supraja Ranganathan for editorial comments on the manuscript. Oligonucleotides were synthesized by the DNA/Peptide Facility, part of the Health Science Center Cores at the University of Utah. Sequencing was performed by the IGBMC Microarray and Sequencing platform, a member of the "France Génomique" consortium (ANR-10-INBS-0009). This work was supported by funds to B.L.B. from the National Institute of General Medical Sciences (R01GM121706), and funds to H.M.D from a National Institutes of Health Institutional Training Grant (T32GM122740). This work was performed under the framework of the LABEX: ANR-10-LABX-0036_NETRNA, which benefits from funding from the state, managed by the French National Research Agency as part of the Investments for the future program. This work also received funding from the French Minister for Higher Education, Research and Innovation (PhD contract to L.T. and M.B.) and the Hoffmann Infinitus Program (L.T.).

Received July 14, 2020; accepted August 20, 2020.

\section{REFERENCES}

Ahmad S, Hur S. 2015. Helicases in antiviral immunity: dual properties as sensors and effectors. Trends Biochem Sci 40: 576-585. doi:10 .1016/j.tibs.2015.08.001

Baum A, Sachidanandam R, García-Sastre A. 2010. Preference of RIG-I for short viral RNA molecules in infected cells revealed by nextgeneration sequencing. Proc Natl Acad Sci 107: 16303-16308. doi:10.1073/pnas.1005077107

Bolger AM, Lohse M, Usadel B. 2014. Trimmomatic: a flexible trimmer for Illumina sequence data. Bioinformatics 30: 2114-2120. doi:10 .1093/bioinformatics/btu170

Bronkhorst AW, Vogels R, Overheul GJ, Pennings B, GaussonDorey V, Miesen P, van Rij RP. 2019. A DNA virus-encoded immune antagonist fully masks the potent antiviral activity of RNAi in Drosophila. Proc Natl Acad Sci 116: 24296-24302. doi:10 .1073/pnas.1909183116

Carthew RW, Sontheimer EJ. 2009. Origins and mechanisms of miRNAs and siRNAs. Cell 136: 642-655. doi:10.1016/j.cell.2009 .01 .035

Cenik ES, Fukunaga R, Lu G, Dutcher R, Wang Y, Tanaka Hall TM, Zamore PD. 2011. Phosphate and R2D2 restrict the substrate specificity of Dicer-2, an ATP-driven ribonuclease. Mol Cell 42: 172184. doi:10.1016/j.molcel.2011.03.002

Chung WJ, Okamura K, Martin R, Lai EC. 2008. Endogenous RNA interference provides a somatic defense against Drosophila transposons. Curr Biol 18: 795-802. doi:10.1016/j.cub.2008.05.006

Czech B, Malone CD, Zhou R, Stark A, Schlingeheyde C, Dus M, Perrimon N, Kellis M, Wohlschlegel JA, Sachidanandam R, et al. 2008. An endogenous small interfering RNA pathway in Drosophila. Nature 453: 798-802. doi:10.1038/nature07007

Deddouche S, Matt N, Budd A, Mueller S, Kemp C, Galiana-Arnoux D Dostert C, Antoniewski C, Hoffmann JA, Imler JL. 2008. The DExD/H-box helicase Dicer-2 mediates the induction of antiviral activity in Drosophila. Nat Immunol 9: 1425-1432. doi:10.1038/ ni.1664

Fairman-Williams ME, Guenther UP, Jankowsky E. 2010. SF1 and SF2 helicases: family matters. Curr Opin Struct Biol 20: 313-324. doi:10.1016/j.sbi.2010.03.011
Fukunaga R, Han BW, Hung JH, Xu J, Weng Z, Zamore PD. 2012. Dicer partner proteins tune the length of mature miRNAs in flies and mammals. Cell 151: 533-546. doi:10.1016/j.cell.2012.09.027

Fukunaga R, Colpan C, Han BW, Zamore PD. 2014. Inorganic phosphate blocks binding of pre-miRNA to Dicer-2 via its PAZ domain. EMBO J 33: 371-384. doi:10.1002/embj.201387176

Galiana-Arnoux D, Dostert C, Schneemann A, Hoffmann JA, Imler JL. 2006. Essential function in vivo for Dicer-2 in host defense against RNA viruses in Drosophila. Nat Immunol 7: 590-597. doi:10.1038/ ni1335

Ghildiyal M, Seitz H, Horwich MD, Li C, Du T, Lee S, Xu J, Kittler ELW, Zapp ML, Weng Z, et al. 2008. Endogenous siRNAs derived from transposons and mRNAs in Drosophila somatic cells. Science 320: 1077-1081. doi:10.1126/science.1157396

Girardi E, Lefèvre M, Chane-Woon-Ming B, Paro S, Claydon B, Imler JL, Meignin C, Pfeffer S. 2015. Cross-species comparative analysis of Dicer proteins during Sindbis virus infection. Sci Rep 5: 1-12. doi:10.1038/srep10693

Golden DE, Gerbasi VR, Sontheimer EJ. 2008. An inside Job for siRNAs. Mol Cell 31: 309-312. doi:10.1016/j.molcel.2008.07.008

Goto A, Okado K, Martins N, Cai H, Barbier V, Lamiable O, Troxler L, Santiago E, Kuhn L, Paik D, et al. 2018. The kinase IKK $\beta$ regulates a STING- and NF-KB-dependent antiviral response pathway in Drosophila. Immunity 49: 225-234.e4. doi:10.1016/j.immuni .2018.07.013

Han Y-H, Luo Y-J, Wu Q, Jovel J, Wang X-H, Aliyari R, Han C, Li W-X, Ding S-W. 2011. RNA-based immunity terminates viral infection in adult Drosophila in the absence of viral suppression of RNA interference: characterization of viral small interfering RNA populations in wild-type and mutant flies. J Virol 85: 13153-13163. doi:10 .1128/JVI.05518-11

Hansen SR, Aderounmu AM, Donelick HM, Bass BL. 2020. Dicer's helicase domain: a meeting place for regulatory proteins. Cold Spring Harb Symp Quant Biol 84: 039750.

Harrington AW, McKain MR, Michalski D, Bauer KM, Daugherty JM, Steiniger M. 2017. Drosophila melanogaster retrotransposon and inverted repeat-derived endogenous siRNAs are differentially processed in distinct cellular locations. BMC Genomics 18: 304320. doi:10.1186/s12864-017-3692-8

Hartig JV, Förstemann K. 2011. Loqs-PD and R2D2 define independent pathways for RISC generation in Drosophila. Nucleic Acids Res 39: 3836-3851. doi:10.1093/nar/gkq1324

Hartig JV, Esslinger S, Böttcher R, Saito K, Förstemann K. 2009. EndosiRNAs depend on a new isoform of loquacious and target artificially introduced, high-copy sequences. EMBO J 28: 29322944. doi:10.1038/emboj.2009.220

Jankowsky E. 2011. RNA helicases at work: binding and rearranging. Trends Biochem Sci 36: 19-29. doi:10.1016/j.tibs.2010.07.008

Jia H, Kolaczkowski O, Rolland J, Kolaczkowski B. 2017. Increased affinity for RNA targets evolved early in animal and plant dicer lineages through different structural mechanisms. Mol Biol Evol 34: 3047-3063. doi:10.1093/molbev/msx187

Jiang F, Ramanathan A, Miller MT, Tang GQ, Gale M, Patel SS, Marcotrigiano J. 2011. Structural basis of RNA recognition and activation by innate immune receptor RIG-I. Nature 479: 423-427. doi:10.1038/nature10537

Kandasamy SK, Fukunaga R. 2016. Phosphate-binding pocket in Dicer-2 PAZ domain for high-fidelity siRNA production. Proc Natl Acad Sci 113: 14031-14036. doi:10.1073/pnas.1612393113

Kawamura Y, Saito K, Kin T, Ono Y, Asai K, Sunohara T, Okada TN, Siomi MC, Siomi H. 2008. Drosophila endogenous small RNAs bind to Argonaute 2 in somatic cells. Nature 453: 793-797. doi:10.1038/nature06938

Kemp C, Mueller S, Goto A, Barbier V, Paro S, Bonnay F, Dostert C, Troxler L, Hetru C, Meignin C, et al. 2013. Broad RNA 
interference-mediated antiviral immunity and virus-specific inducible responses in Drosophila. J Immunol 190: 650-658. doi:10 .4049/jimmunol.1102486

Langmead B, Trapnell C, Pop M, Salzberg SL. 2009. Ultrafast and memory-efficient alignment of short DNA sequences to the human genome. Genome Biol 10: R25. doi:10.1186/gb-2009-10-3-r25

Lässig C, Matheisl S, Sparrer KMJ, de Oliveira Mann CC, Moldt M, Patel JR, Goldeck M, Hartmann G, García-Sastre A, Hornung V, et al. 2015. ATP hydrolysis by the viral RNA sensor RIG-I prevents unintentional recognition of self-RNA. eLife 4: e10859. doi:10 .7554/eLife.10859

Lee YS, Carthew RW. 2003. Making a better RNAi vector for Drosophila: use of intron spacers. Methods 30: 322-329. doi:10 .1016/S1046-2023(03)00051-3

Lee YS, Nakahara K, Pham JW, Kim K, He Z, Sontheimer EJ, Carthew RW. 2004. Distinct roles for Drosophila Dicer-1 and Dicer-2 in the siRNA/miRNA silencing pathways. Cell 117: 6981. doi:10.1016/S0092-8674(04)00261-2

Linder P, Jankowsky E. 2011. From unwinding to clamping-the DEAD box RNA helicase family. Nat Rev Mol Cell Biol 12: 505516. doi:10.1038/nrm3154

Liu Q, Rand TA, Kalidas S, Du F, Kim HE, Smith DP, Wang X. 2003. R2D2, a bridge between the initiation and effector steps of the Drosophila RNAi pathway. Science 301: 1921-1925. doi:10 $.1126 /$ science. 1088710

Liu X, Jiang F, Kalidas S, Smith D, Liu Q. 2006. Dicer-2 and R2D2 coordinately bind siRNA to promote assembly of the siRISC complexes. RNA 12: 1514-1520. doi:10.1261/rna.101606

Luo D, Kohlway A, Pyle AM. 2013. Duplex RNA activated ATPases (DRAs): platforms for RNA sensing, signaling and processing. RNA Biol 10: 111-120. doi:10.4161/rna.22706

Maas WK. 1948. Spectrophotometric and chromatographic adsorption analysis of the red eye pigment of Drosophila melanogaster. Genetics 33: 177-190.

Marques JT, Wang JP, Wang X, de Oliveira KPV, Gao C, Aguiar ERGR, Jafari N, Carthew RW. 2013. Functional specialization of the small interfering RNA pathway in response to virus infection. PLoS Pathog 9: e1003579. doi:10.1371/journal.ppat.1003579

Mongelli V, Saleh M-C. 2016. Bugs are not to be silenced: small RNA pathways and antiviral responses in insects. Annu Rev Virol 3: 573589. doi:10.1146/annurev-virology-110615-042447

Mueller S, Gausson V, Vodovar N, Deddouchea S, Troxler L, Perot J, Pfeffer S, Hoffmann JA, Saleh MC, Imler JL. 2010. RNAi-mediated immunity provides strong protection against the negative-strand RNA vesicular stomatitis virus in Drosophila. Proc Natl Acad Sci 107: 19390-19395. doi:10.1073/pnas.1014378107

Mussabekova A, Daeffler L, Imler JL. 2017. Innate and intrinsic antiviral immunity in Drosophila. Cell Mol Life Sci 74: 2039-2054. doi:10 .1007/s00018-017-2453-9

Nakashima N, Shibuya N. 2006. Multiple coding sequences for the genome-linked virus protein (VPg) in dicistroviruses. J Invertebr Pathol 92: 100-104. doi:10.1016/j.jip.2006.03.003

Nicholson AW. 2014. Ribonuclease III mechanisms of double-stranded RNA cleavage. Wiley Interdiscip Rev RNA 5: 31-48. doi:10 $.1002 /$ wrna. 1195

Nishida KM, Miyoshi K, Ogino A, Miyoshi T, Siomi H, Siomi MC. 2013. Roles of R2D2, a cytoplasmic D2 body component, in the endogenous siRNA pathway in Drosophila. Mol Cell 49: 680-691. doi:10 .1016/j.molcel.2012.12.024

Okamura K, Chung WJ, Ruby JG, Guo H, Bartel DP, Lai EC. 2008. The Drosophila hairpin RNA pathway generates endogenous short interfering RNAs. Nature 453: 803-806. doi:10.1038/nature07015

Petrillo JE, Venter PA, Short JR, Gopal R, Deddouche S, Lamiable O, Imler J-L, Schneemann A. 2013. Cytoplasmic granule formation and translational inhibition of nodaviral RNAs in the absence of the double-stranded RNA binding protein B2. J Virol 87: 1340913421. doi:10.1128/JVI.02362-13

Poirier EZ, Goic B, Tomé-Poderti L, Frangeul L, Boussier J, Gausson V, Blanc H, Vallet T, Loyd H, Levi LI, et al. 2018. Dicer-2-dependent generation of viral DNA from defective genomes of RNA viruses modulates antiviral immunity in insects. Cell Host Microbe 23: 353-365.e8. doi:10.1016/j.chom.2018.02.001

Sabin LR, Zheng Q, Thekkat P, Yang J, Hannon GJ, Gregory BD, Tudor M, Cherry S. 2013. Dicer-2 processes diverse viral RNA species. PLoS One 8: e55458. doi:10.1371/journal.pone.0055458

Schlee M. 2013. Master sensors of pathogenic RNA-RIG-I like receptors. Immunobiology 218: 1322-1335. doi:10.1016/j.imbio.2013 .06 .007

Sinha NK, Bass BL. 2017. Overexpression and purification of Dicer and accessory proteins for biochemical and structural studies. Methods 126: 54-65. doi:10.1016/j.ymeth.2017.07.012

Sinha NK, Trettin KD, Aruscavage PJ, Bass BL. 2015. Drosophila dicer2 cleavage is mediated by helicase- and dsRNA termini-dependent states that are modulated by loquacious-PD. Mol Cell 58: 406-417. doi:10.1016/j.molcel.2015.03.012

Sinha NK, Iwasa J, Shen PS, Bass BL. 2018. Dicer uses distinct modules for recognizing dsRNA termini. Science 359: 329-334. doi:10 .1126/science.aaq0921

Talide L, Imler JL, Meignin C. 2020. Sensing viral infections in insects: a dearth of pathway receptors. Insect Mol Virol Adv Emerg Trends 34: 31-60. doi:10.21775/cimb.034.031

Trettin KD, Sinha NK, Eckert DM, Apple SE, Bass BL. 2017. Loquacious-PD facilitates Drosophila Dicer-2 cleavage through interactions with the helicase domain and dsRNA. Proc Natl Acad Sci 114: E7939-E7948. doi:10.1073/pnas.1707063114

Van Rij RP, Saleh MC, Berry B, Foo C, Houk A, Antoniewski C, Andino R. 2006. The RNA silencing endonuclease Argonaute 2 mediates specific antiviral immunity in Drosophila melanogaster. Genes Dev 20: 2985-2995. doi:10.1101/gad.1482006

Vodovar N, Goic B, Blanc H, Saleh M-C. 2011. In silico reconstruction of viral genomes from small RNAs improves virus-derived small interfering RNA profiling. J Virol 85: 11016-11021. doi:10.1128/JVI 05647-11

Wang XH, Aliyari R, Li WX, Li HW, Kim K, Carthew R, Atkinson P, Ding SW. 2006. RNA interference directs innate immunity against viruses in adult Drosophila. Science 312: 452-454. doi:10.1126/ science. 1125694

Watanabe T, Totoki Y, Toyoda A, Kaneda M, Kuramochi-Miyagawa S, Obata Y, Chiba H, Kohara Y, Kono T, Nakano T, et al. 2008. Endogenous siRNAs from naturally formed dsRNAs regulate transcripts in mouse oocytes. Nature 453: 539-543. doi:10.1038/ nature06908

Weber M, Gawanbacht A, Habjan M, Rang A, Borner C, Schmidt AM, Veitinger S, Jacob R, Devignot S, Kochs G, et al. 2013. Incoming RNA virus nucleocapsids containing a $5^{\prime}$-triphosphorylated genome activate RIG-I and antiviral signaling. Cell Host Microbe 13: 336-346. doi:10.1016/j.chom.2013.01.012

Weber-Gerlach M, Weber F. 2016. Standing on three legs: antiviral activities of RIG-I against influenza viruses. Curr Opin Immunol 42: 71-75. doi:10.1016/j.coi.2016.05.016

Welker NC, Maity TS, Ye X, Aruscavage PJ, Krauchuk AA, Liu Q, Bass BL. 2011. Dicer's helicase domain discriminates dsRNA termini to promote an altered reaction mode. Mol Cell 41: 589-599. doi:10.1016/j.molcel.2011.02.005

Xu J, Cherry S. 2014. Viruses and antiviral immunity in Drosophila. Dev Comp Immunol 42: 67-84. doi:10.1016/j.dci.2013.05.002

Zhou R, Czech B, Brennecke J, Sachidanandam R, Wohlschlegel JA, Perrimon N, Hannon GJ. 2009. Processing of Drosophila endosiRNAs depends on a specific Loquacious isoform. RNA 15: 1886-1895. doi:10.1261/rna.1611309 

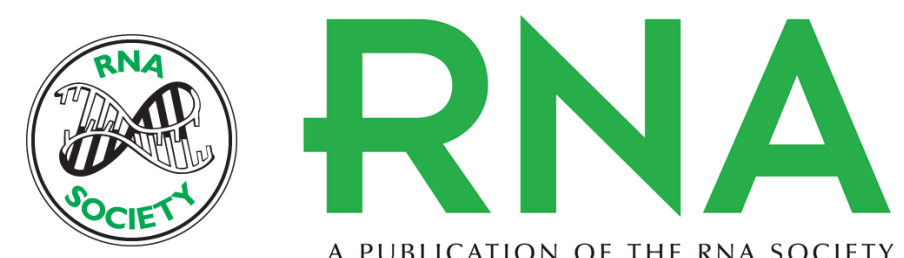

A PUBLICATION OF THE RNA SOCIETY

\section{In vitro studies provide insight into effects of Dicer-2 helicase mutations in Drosophila melanogaster}

Helen M. Donelick, Loïc Talide, Matthieu Bellet, et al.

RNA 2020 26: 1847-1861 originally published online August 25, 2020

Access the most recent version at doi:10.1261/rna.077289.120

\section{Supplemental http://rnajournal.cshlp.org/content/suppl/2020/08/25/rna.077289.120.DC1 \\ Material}

References This article cites 63 articles, 17 of which can be accessed free at: http://rnajournal.cshlp.org/content/26/12/1847.full.html\#ref-list-1

Creative This article is distributed exclusively by the RNA Society for the first 12 months after the Commons

License full-issue publication date (see http://rnajournal.cshlp.org/site/misc/terms.xhtml). After 12 months, it is available under a Creative Commons License (Attribution-NonCommercial 4.0 International), as described at http://creativecommons.org/licenses/by-nc/4.0/. Email Alerting $\begin{aligned} & \text { Receive free email alerts when new articles cite this article - sign up in the box at the } \\ & \text { Service }\end{aligned}$ top right corner of the article or click here. 